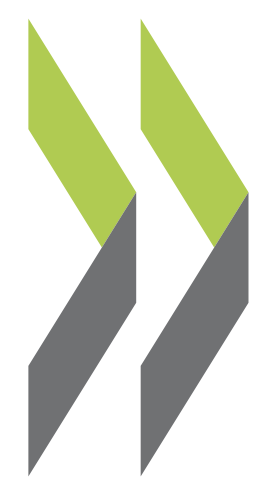

OECD Economics Department Working Papers No. 722

Improving the Performance of the Public Health Care System in Greece

Charalampos Economou, Claude Giorno 
Organisation de Coopération et de Développement Économiques

Organisation for Economic Co-operation and Development

21-Sep-2009

ECONOMICS DEPARTMENT

English - Or. English

IMPROVING THE PERFORMANCE OF THE PUBLIC HEALTH CARE SYSTEM IN GREECE

ECONOMICS DEPARTMENT WORKING PAPER No. 722

By Charalampos Economou and Claude Giorno

All Economics Department Working Papers are available through OECD's internet web site at www.oecd.org/Working_Papers

JT03269899

Document complet disponible sur OLIS dans son format d'origine

Complete document available on OLIS in its original format 


\section{ABSTRACT/RÈSUMÉ \\ Improving the performance of the public health care system in Greece}

Greek health outcomes compare favourably with the OECD average. However, the health care system is seen as not working well by the population. One source of dissatisfaction is the high proportion of private household spending on health, including informal payments, while public health spending relative to GDP is one of the lowest in the OECD. This situation leads to inequities in access to certain medical services. Also, there is a weakening of efficiency of the system, which should be addressed sooner than later in view of a rising demand for medical services, which is going to intensify in the coming decades, and the need to keep government health care spending in check. This calls for reforms in four areas: (i) reviewing the excessively fragmented structure of the health care system and its governance; (ii) enhancing the quality of public primary health care services; (iii) modernising hospital administration; and (iv) further tightening control over pharmaceutical expenditure.

This Working Paper relates to the 2009 Economic Survey of Greece.

(www.oecd.org/eco/surveys/Greece)

JEL classification: I10; I12; I18; I19.

Keywords: Health care system; health policy; hospital; primary health care; pharmaceutical expenditure; generic drugs; medical prevention; copayment; referral system; prescription system; Data Envelopment Analysis; excise tax; health insurance funds; National health system; medical demography; general practitioners.

**********************************************************

\section{Améliorer la performance du système public de santé en Grèce}

Les résultats de la Grèce dans le domaine de la santé se comparent favorablement avec la moyenne de l'OCDE. Cependant, le fonctionnement du système de soins n'est pas satisfaisant selon la population. Une source d'insatisfaction concerne la proportion élevée des dépenses privées de santé des ménages, y compris des paiements informels, alors que les dépenses médicales publiques en proportion du PIB sont parmi les plus faibles de l'OCDE. Cette situation conduit à des problèmes d'équité d'accès à certains services médicaux. On observe aussi une baisse d'efficacité du système à laquelle il import de remédier au plus tôt compte tenu de la hausse de la demande de soins, qui devrait s'intensifier au cours des prochaines décennies et du besoin de contrôle sur la croissance des dépenses publiques de santé. Ceci milite en faveur de réforme dans quatre domaines : (i) réviser la structure très fragmentée du système de soins et sa gouvernance; (ii) améliorer la qualité des services publics de soins primaires; (iii) moderniser l'administration hospitalière ; et (iv) renforcer davantage le contrôle sur les dépenses pharmaceutiques.

Ce document de travail se rapporte à l'Étude économique de l'OCDE de la Grèce 2009 (www.oecd.org/eco/etudes/Grèce)

Classification JEL : I10 ; I12 ; I18 ; I19.

Mots clés : Système de santé; politique de santé; hôpital; soins primaires de santé; dépenses pharmaceutiques ; génériques ; prévention médicale ; co-paiement ; système de médecin référant ; Analyse d'enveloppement des données; accises ; caisses d'assurance médicales ; système national de santé ; démographie médicale; médecins généralistes.

\section{Copyright OECD 2009}

Application for permission to reproduce or translate all, or part of, this material should be made to: Head of Publications Service, OECD, 2 rue André-Pascal, 75775 Paris Cedex 16, France. 


\section{TABLE OF CONTENTS}

Improving the performance of the public health care system in Greece .......................................................5

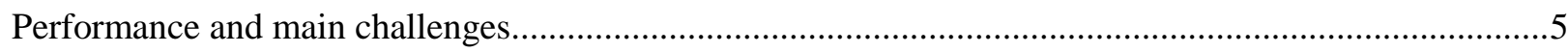

The organisation of the health care system impairs its efficiency .......................................................12

The fragmented structure of the health care system is a source of inefficiency ..................................12

Control over public health spending is steeped in bureaucracy .........................................................

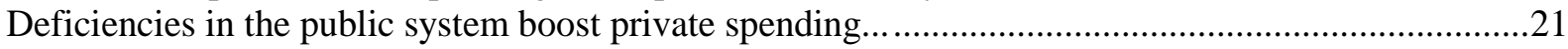

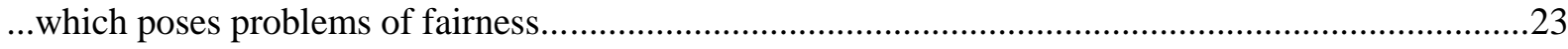

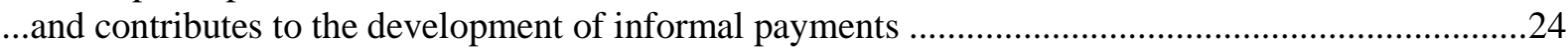

The quality and efficiency of public health care services need to be improved ......................................25

The shortcomings of public primary health care services have to be remedied ....................................25

Hospital funding should be rationalised and its management professionalised ..................................27

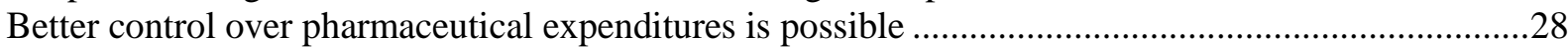

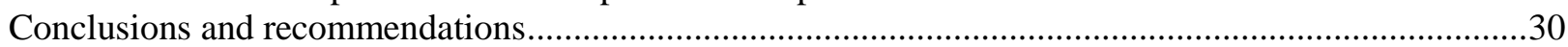

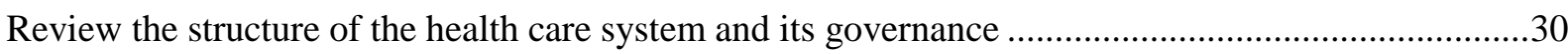

Enhance the quality of public primary health care services ...............................................................

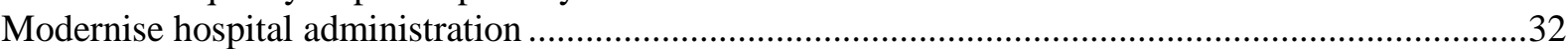

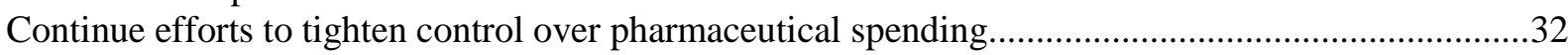

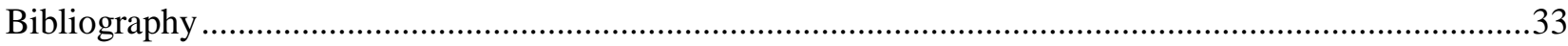

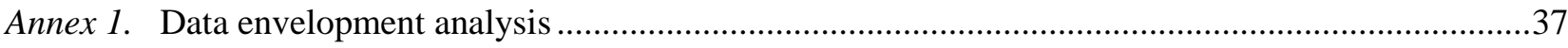

Annex 2. A new mechanism for monitoring prescriptions for drugs ..........................................................39

\section{Figures}

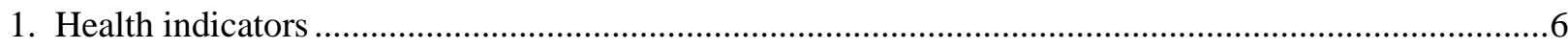

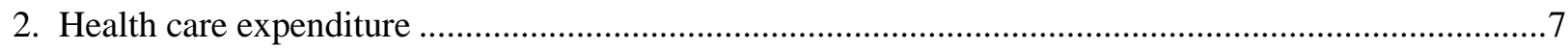

3. Efficiency measures of the Greek health system in an international perspective .................................

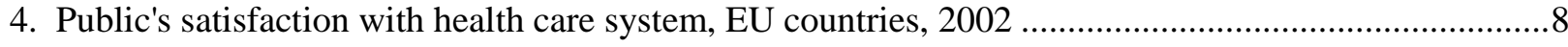

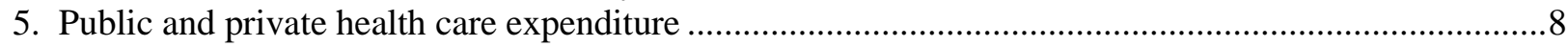

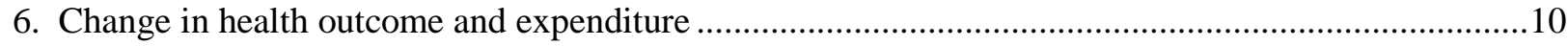

7. Efficiency development since 1990: Data Envelopment Analysis ....................................................11

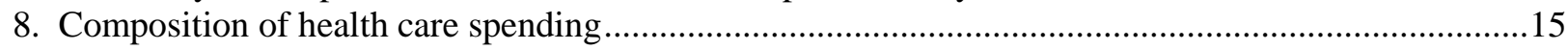

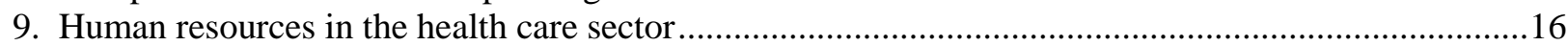

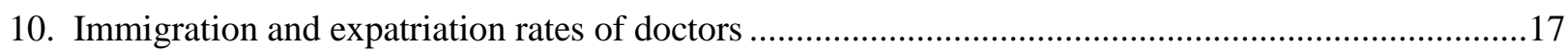

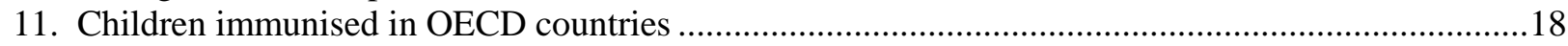

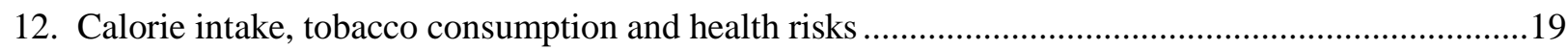

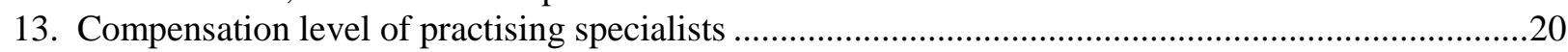

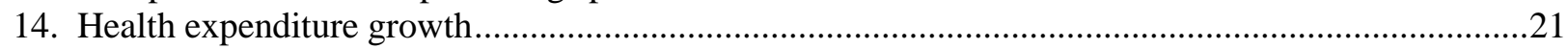

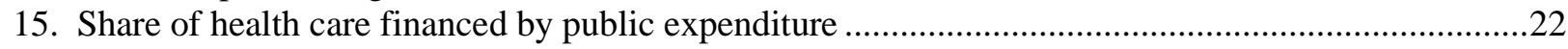

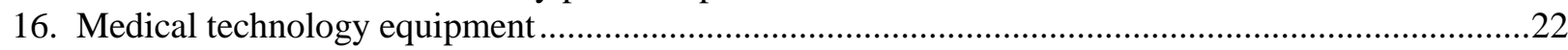

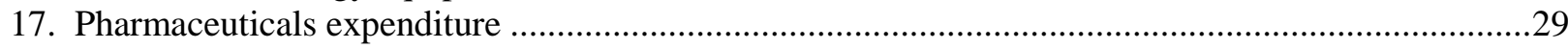

A1.1. A stylised example of an efficiency frontier and non-increasing returns to scale .........................37 
ECO/WKP(2009)63

\section{Boxes}

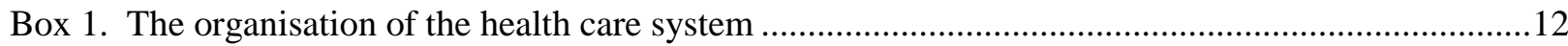

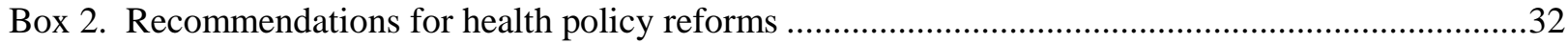


ECO/WKP(2009)63

\title{
Improving the performance of the public health care system in Greece
}

\author{
By Charalampos Economou and Claude Giorno ${ }^{1}$
}

\section{Performance and main challenges}

1. Health outcomes in Greece compare favourably in international comparison. The population's health status, as measured by reliable and internationally comparable indicators, is better, on the whole, than the OECD average (Figure 1). Life expectancy at birth, which reached 79.6 years in 2006, is higher than the area average. The infant mortality rate is lower than in many countries with high living standards, such as Australia, Canada, the United Kingdom and the United States. Disparity in outcomes by gender also seems less pronounced than in the OECD average, as shown by life expectancy both at birth and at age 65. The level of aggregate health spending is in line with per capita income (Figure 2).

2. At first sight, the Greek health care system seems relatively efficient in international comparison. A recent OECD empirical study (Joumard et al., 2008), based on panel data analysis, highlights the significant impact of medical spending, living standards and educational levels, tobacco and alcohol consumption, diet and pollution on the health indicators of each country. For Greece, predictions made by the model with regard to indicators such as life expectancy fall below the values actually observed, which would suggest that the health care system is relatively effective by international standards (Figure 3 , Part A). Moreover, these findings are corroborated by Afonso et al. (2003), which ranked Greece sixth out of 23 OECD countries for the efficiency of the health care system. These conclusions need to be interpreted cautiously, however, due to the limitations imposed by data availability. ${ }^{2}$ As recognised by Joumard et al. (2008), these findings are only partially confirmed by an alternative assessment based on data envelopment analysis (DEA), which would suggest that the efficiency of the Greek health care system is similar to that of the OECD average, and that life expectancy could improve by up to three years (Figure 3, Part B) if the system's efficiency were upgraded to the level of the best performing countries.

1. The paper was originally produced for the 2009 OECD Economic Survey of Greece, published in July 2009 under the authority of the Economic and Development Review Committee of the OECD. Charalampos Economou is currently assistant professor at the Panteion University of Athens and Claude Giorno is the head of the Greece Desk in the Economics Department of the OECD. We would like to thank, without implicating, Andrew Dean, Bob Ford, Peter Hoeller, Piritta Sorsa, Isabelle Joumard, Valérie Paris, Christophe André, Vivian Koutsogeorgopoulou and Greek government officials for valuable comments and/or discussions. We are also grateful to Marie-Christine Bonnefous, Joseph Chien and Agnès Cavaciuti for technical assistance and to Deirdre Claassen for secretarial assistance.

2. As acknowledged in Joumard et al. (2008), the usual health indicators provide incomplete information on the benefits delivered by health care systems; they convey nothing about quality-of-life gains or how medical services are distributed in the population. The linkages between these indicators and their potential determinants, such as pollution or smoking, also pose delicate problems: for instance, emissions provide only an imperfect reflection of the degree of the population's exposure to pollution. Likewise, the data available cannot be used to factor in the very long lead time (up to 30 years) of smoking's impact on health. Consequently, the assessments of the efficiency of health care systems that are provided by econometric models are impaired by substantial problems of measurement or omitted variables. 
3. Despite these fairly favourable outcomes, the health care system is seen as not working well by the population. Dissatisfaction, as documented for example by WHO (1996) and Tountas et al., (2005), is more pronounced than in most other countries (Figure 4). This reflects persistent deficiencies in the sector despite the many reforms - or attempted reforms - undertaken over some 15 years, and the inability of care to meet the public's expectations, especially with regard to primary health care services. There is a correlation between patients' assessments of the quality of primary health care and performance of the health care systems for the European countries (WHO, 2004).

Figure 1. Health indicators
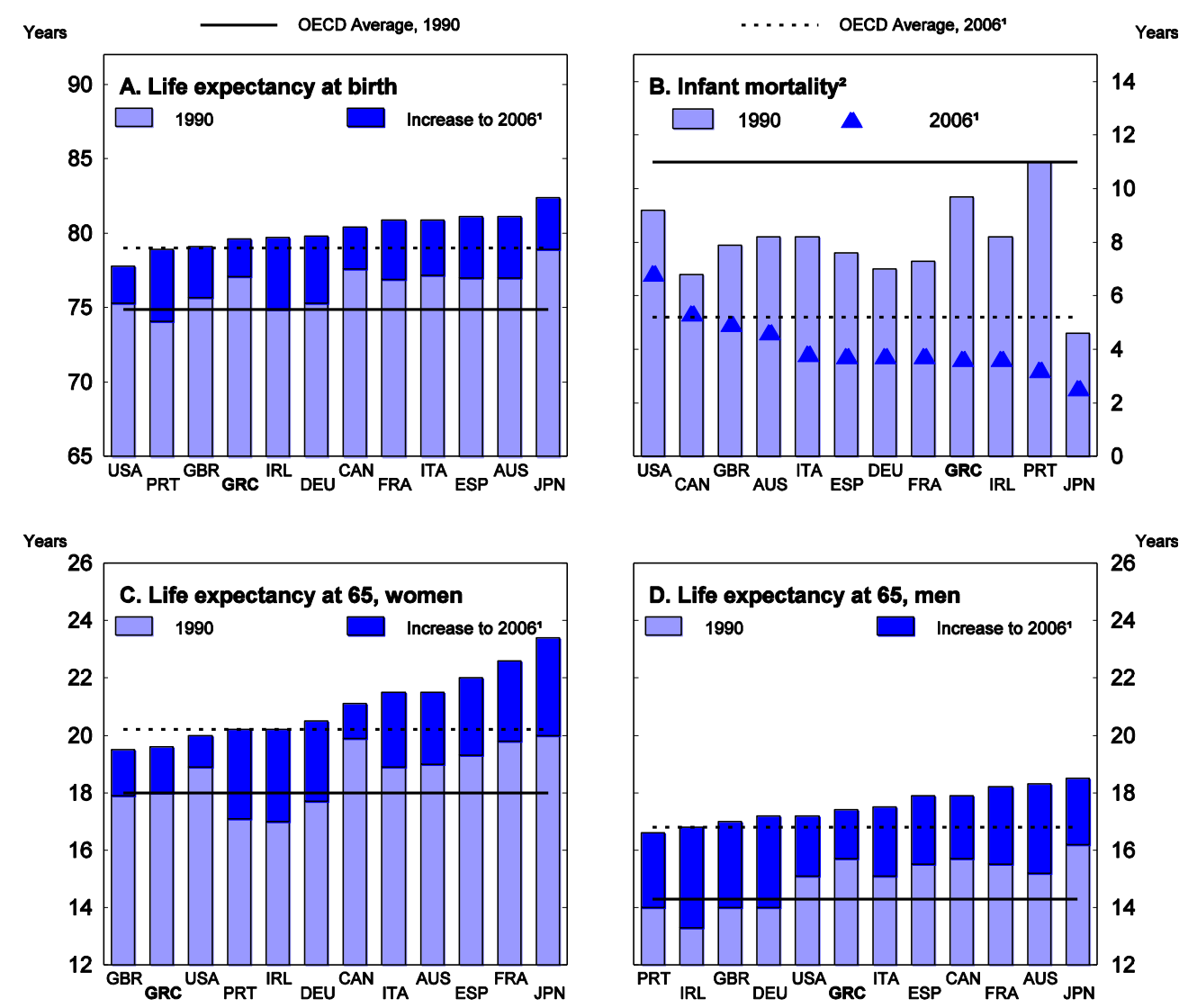

1. 2006 or latest available year.

2. Deaths for 1000 live births.

Source: OECD Health Data 2008. 
Figure 2. Health care expenditure

$2006^{1}$
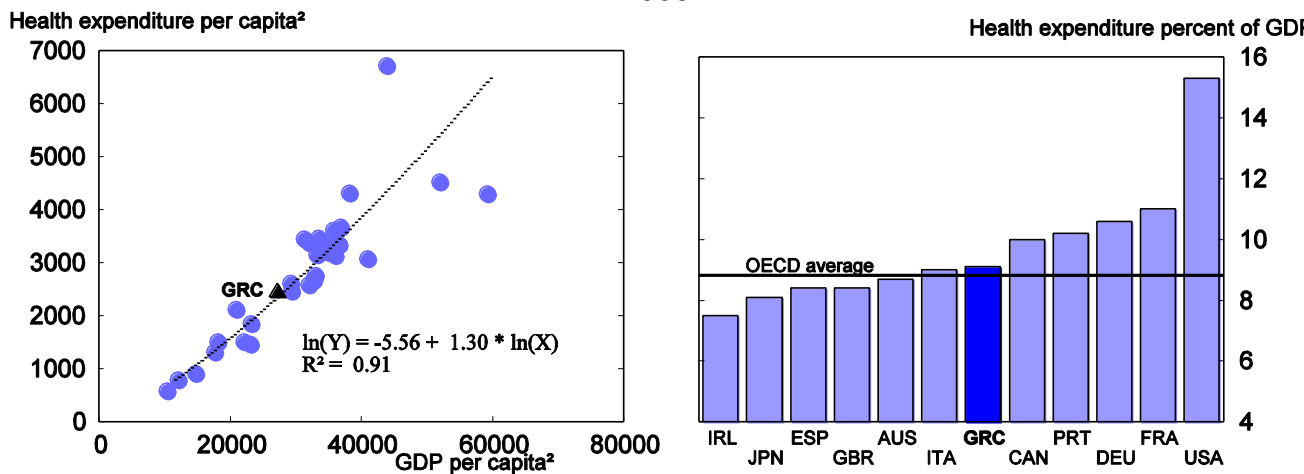

1. 2005 for Turkey, 2004 for Netherlands, 2003 for New Zealand. Estimation for Luxembourg and Switzerland.

2. US\$ current PPPs.

Source: OECD Health Data 2008.

Figure 3. Efficiency measures of the Greek health system in an international perspective
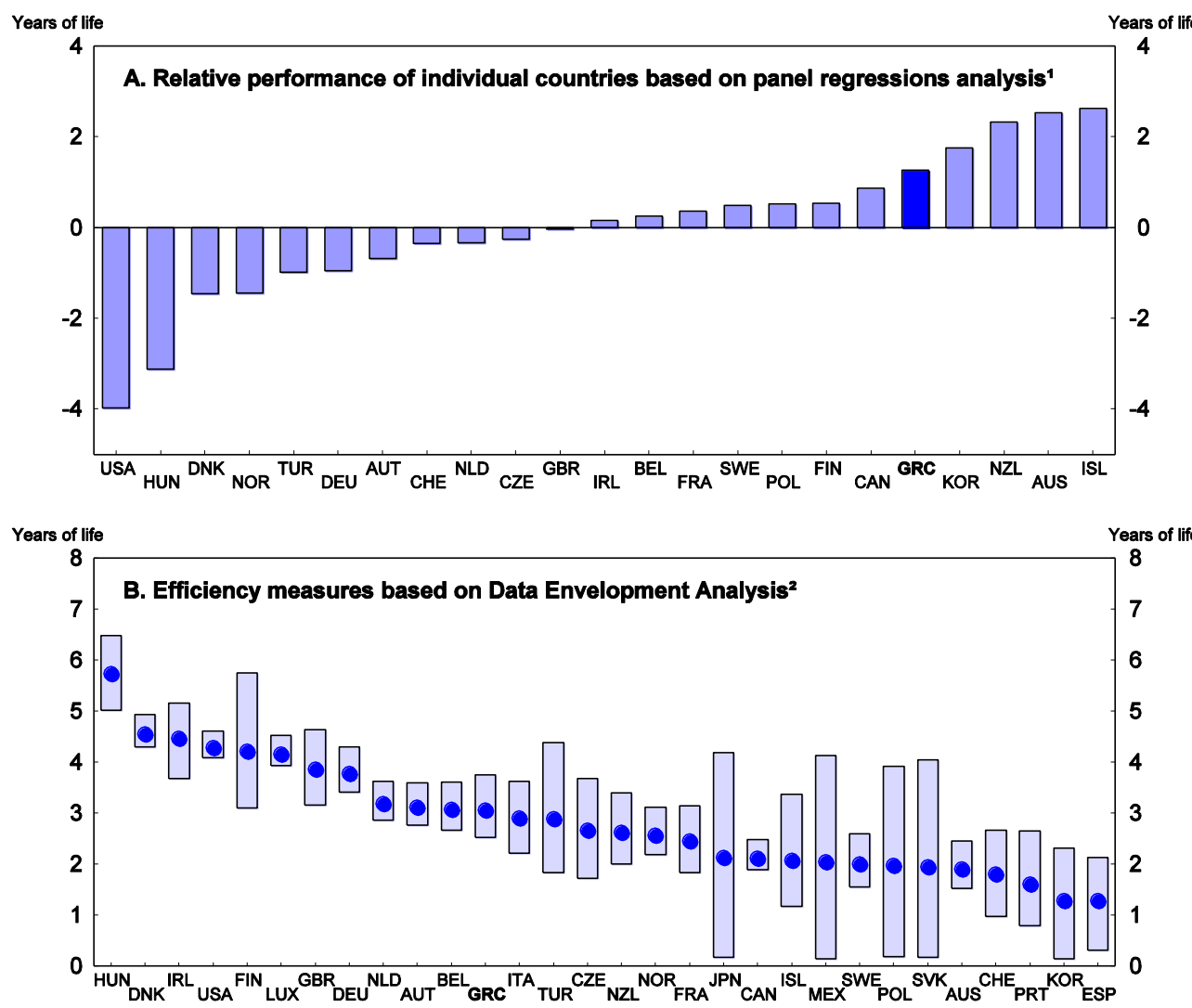

1. Model residuals and country fixed-effects deviations from averages are added and considered as a proxy for relative efficiency (i.e. the years shown in the above figure can be viewed as years of life that would be saved (or lost) if country i was as efficient as the OECD average).

2. DEA performed with three inputs (health care spending, Economic, Social and Cultural Status, consumption of fruits and vegetables) and one output (life expectancy at birth). Dots in the figure provide point estimate of the potential efficiency gains measured in number of years of life. Bars provide confidence intervals for the efficiency scores.

Source: OECD Calculations. 
Figure 4. Public's satisfaction with health care system, EU countries, 2002

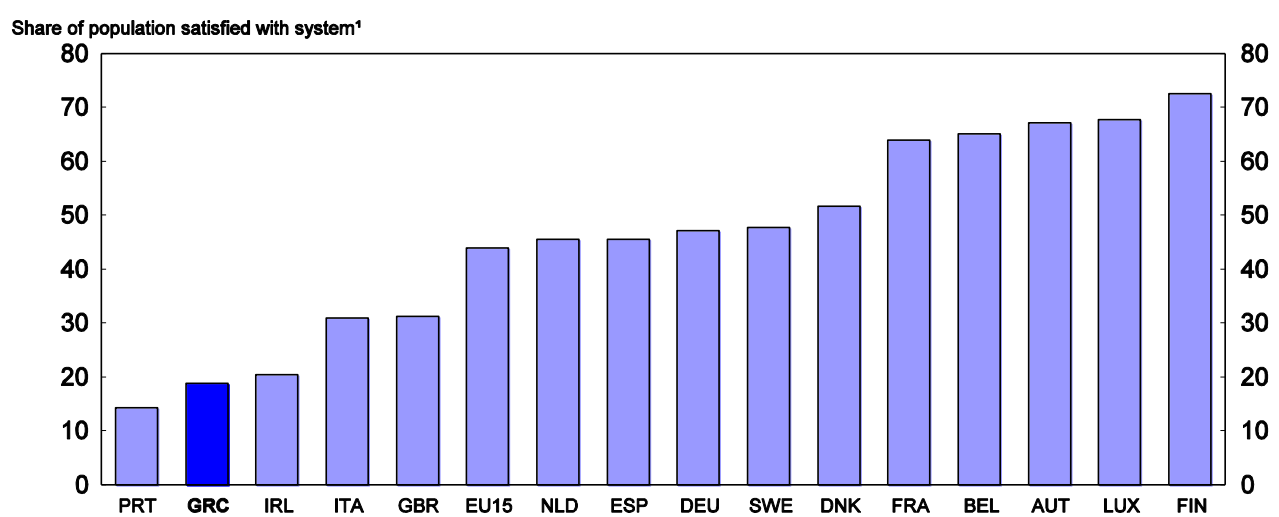

1. Runs and only minor changes would make it work better.

Source: OECD Health 2008, Eurobarometer, 2003.

4. One of the sources of dissatisfaction is related to the high proportion of private household spending on health. Whereas the health care system has been designed to guarantee free access to medical services for the entire population, in 2006 over 38\% of aggregate health spending was private, and those outlays accounted for 3.5\% of GDP (Figure 5). Only the United States, Switzerland and Mexico had higher levels of private spending in the OECD. In addition, over $90 \%$ of those outlays consist of direct payments by households, compared with less than $80 \%$ in the OECD average. This situation in part reflects the imperative need for budget consolidation in Greece. Government spending on health care accounted for only $5.6 \%$ of GDP in 2006 - one of the lowest percentages in the OECD. Yet this constraint is posing difficulties, in particular as regards fairness.

Figure 5. Public and private health care expenditure Per cent of GDP, $2006^{1}$
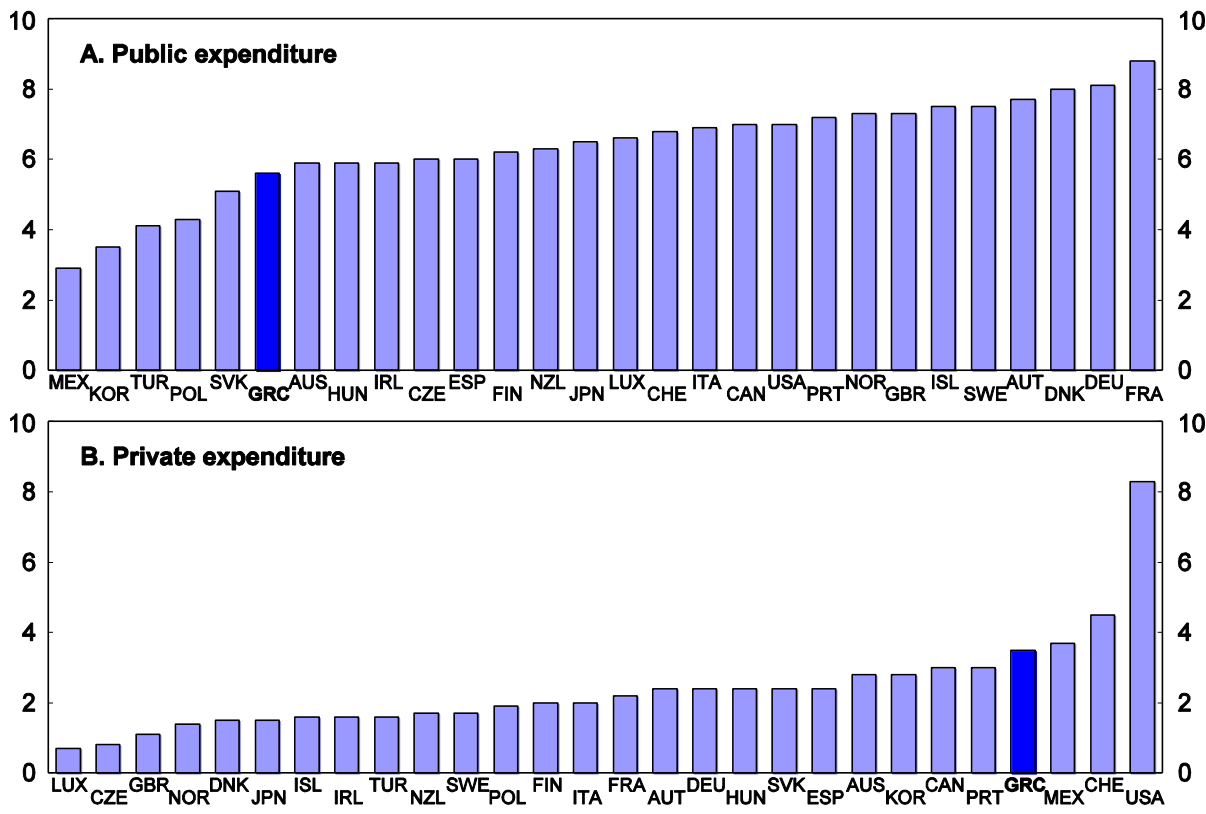

1. 2005 for Turkey.

Source: OECD Health Data, 2008. 
5. The health care system aims at guaranteeing universal and free access to medical services for the entire population. According to Geitona et al. (2007), it is the individual's state of health that is the main determinant of the use of those services, and most studies concur that socio-economic factors have no impact on the use of public-sector hospital care (Pappa and Niakas, 2006). Even so, there is evidence for some inequality amongst the population with regard to the extent and generosity of cover against illness. This fairness problem is exacerbated by the frequent informal transfers ("bribes") paid by insured individuals to get access to public health care services that are theoretically free of charge. As a rule, the high and rising level of private spending, which makes the financing of the health care regressive (Liaropoulos and Tragakes, 1998), is contributing to inequalities of access to some medical services. The use of private hospital services is greater for affluent households and those with private insurance. Hospital outlays financed directly by modest-income families amount to only one-fifth of the more well-off households (GSNE, 2006). According to Siskou et al. (2008), the probability of availing oneself of private hospital care is 2.2 times as high for people who have private insurance as for those who do not. The probability of consulting a private physician is also $50 \%$ to $80 \%$ greater for affluent households than for households with modest income or an elementary level of education. Persons of modest means may also be forced to avail themselves of private health care because of the limited development of public health care networks in some rural areas, waiting lists that can in some cases be long and the poor quality of some of the services (Pappa and Niakas, 2006). In such cases, forced recourse to private services is likely to weigh heavily on the budgets of modest-income families (see below).

6. The limited public resources earmarked for health care militate for continued efforts to optimise their use. Over the past fifteen or so years, however, the gains in life expectancy and the decrease in the number of potential years of life lost have been slower than in the OECD on average despite a greater increase in aggregate health care outlays, which points to erosion of efficiency in the system. Nolte and McKee (2008) also find that the strides made in Greece between the late 1990s and early 2000s to reduce amenable mortality were relatively modest by international standards, especially for men. This trend does not result from catching up on the part of the least advanced countries. Greece has made less progress in the realm of health outcomes than countries that recorded equivalent or better results in 1990, despite a more rapid increase in its spending (Figure 6). 
Figure 6. Change in health outcome and expenditure

1990-2006
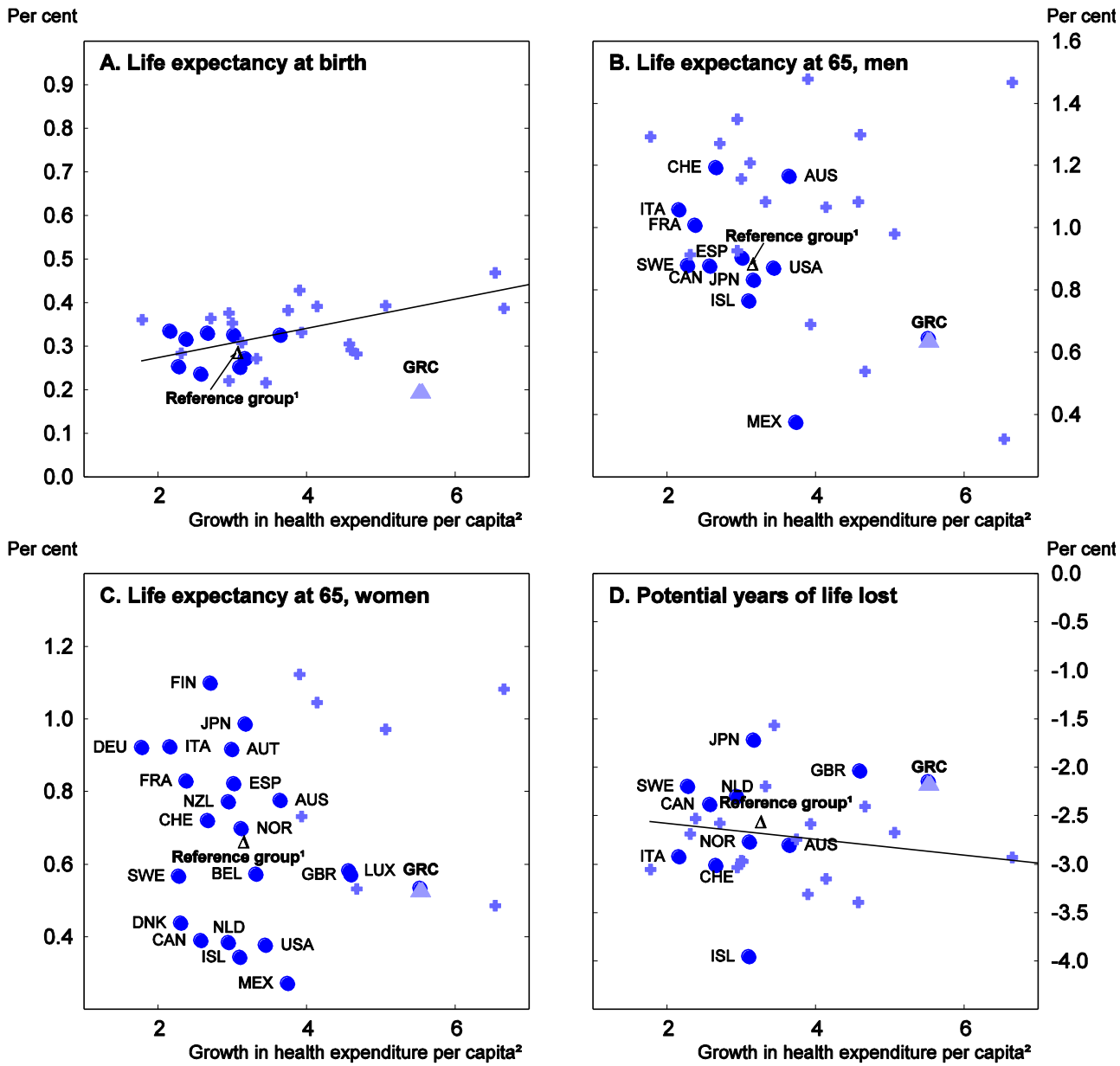

1. The reference group represents the average of countries with similar or better health indicator than Greece in 1990. The names of each country are indicated in each panel except panel A. For this panel the countries are Australia, Canada, France, Italy, Island, Japan, Spain, Sweden, and Switzerland.

2. In 2000 GDP price.

Source: OECD Health Data 2008.

7. The erosion in the effectiveness of the health care system is confirmed by DEA analysis. DEA analysis links health outcomes of the OECD countries to the resources allocated to health care systems and other determinants, such as levels of income or education and lifestyles of populations, by constructing an efficiency frontier for producing medical services from which a measure of efficiency can be derived (Annex 1). This analysis, which is similar to that performed by Joumard et al. (2008), shows that the performance of the Greek health care system, which had ranked between $3^{\text {rd }}$ and $5^{\text {th }}$ among OECD countries in 1990 , had fallen to between $12^{\text {th }}$ and $18^{\text {th }}$ place in 2006 , depending on whether the resources available for health care are measured by the level of spending per capita or proxied by the number of active medical personnel (Figure 7). Whilst in 1990 it was estimated that using the health care resources as efficiently as the best-performing countries would have increased life expectancy at birth by between 0.8 and 0.9 year, the gap widened to between 1.7 and 3 years in $2006 .^{3}$ Moreover, this decline in relative

3. In the case of Greece, the estimated degree of efficiency of the health care system is slightly higher than reported in Joumard et al. (2008) if the resources allocated to health are measured in monetary terms, because the level of aggregate medical expenditure was revised downward after that study was conducted. 
performance seems sharper if resources allocated to health care are measured by the number of active medical personnel. This would suggest that this weaker performance stems more from a decline of technical efficiency rather than higher input costs, i.e. prices and compensation paid for medical services.

Figure 7. Efficiency development since 1990: Data Envelopment Analysis

Potential efficiency gains measured by the number of years of life ${ }^{1}$
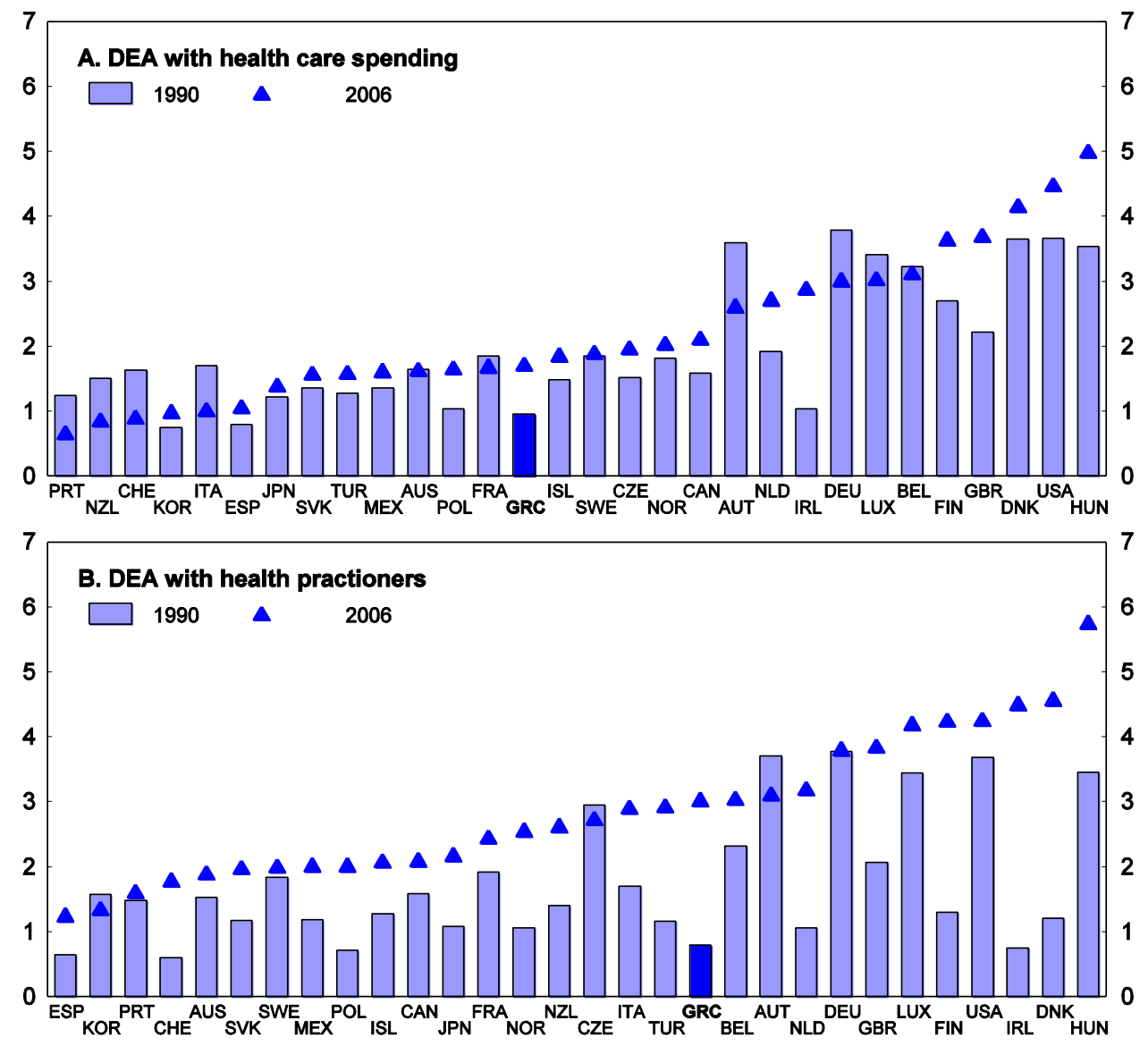

1. Potential efficiency gains (measured in number of year of life expected at birth) by each country the results were aligned on the best performers. A high score indicate a weak efficiency.

Source: OECD Calculations.

8. Declining efficiency as well as fairness issues need to be dealt with in the face of a rising demand for medical services and of the need to keep government health care spending in check. As in other countries, upward pressure on health care spending should indeed remain strong in the coming decades, due primarily to rising living standards, progress in medical technology and higher relative prices for health care services. A simple regression assessing the linkage between health care outlays and income in the OECD countries shows the elasticity of spending per person to per capita GDP (Figure 2) to be 1.3. Demand pressures will also be heightened by population ageing, which are expected to be more pronounced in Greece than for the average of the other OECD countries. According to OECD research, public resources earmarked for health care alone could rise by between $3 \frac{3}{4}$ and $61 / 2$ per cent of GDP by 2050 , to between $91 / 4$ and $12 \%$ of GDP (OECD, 2006a). Guaranteeing the entire population access to quality health care while keeping the cost to public finances in check is thus going to be a major challenge for health care policy in the years ahead. 


\section{The organisation of the health care system impairs its efficiency}

\section{The fragmented structure of the health care system is a source of inefficiency}

9. All OECD countries have to tackle difficult regulatory issues in health. Demand for medical services needs to be channelled through an insurance system, in many cases paid for directly by the government, so that all individuals have access to care, thereby limiting problems of access and providing solidarity amongst the insured. However, this funding structure leads to incentive problems that are aggravated by the asymmetry of information between insurers, health care providers and the insured (or patients). Regulation has a key role to play in the interaction amongst these players to make sure that quality care is available at an affordable cost. Cost control and efficiency are contingent on insurers' ability to negotiate advantageous prices with health care providers and encourage them to enhance their efficiency. It is also important to limit the risks of moral hazard that the system generates by prompting the insured to over consume. Lastly, it is also necessary to avoid excessive medical consumption arising from demand-inducing practices of health care providers. Regulation of both supply and demand is therefore necessary. A proper balance must be struck, however, between incentives intended to enhance efficiency and the quality of care, and those ensuring cost control.

10. The Greek public health care system has a fragmented organisation which makes it difficult to manage incentives coherently. The system (Box 1) does not correspond to a clear regulatory model. Since 1983 it includes a "Beveridgian" integrated National Health System (NHS) serving the entire population and funded largely by the state. This structure, which is similar to the British health care system, should give the government direct control over the supply of primary medical services and over hospital care. However, superimposed on this model is a "Bismarckian" model, involving public insurance funds similar to those in Germany and France, which are funded primarily by social security contributions, and whose spending growth is determined to a large extent by demand. There are over thirty health funds subject to distinct regulations, different contribution rates, cover and conditions for access to the services provided. Affiliation to one of the funds is compulsory and depends on the occupation of the insured. As a result, and in contrast to the situation in some other countries, the existence of multiple funds does not serve to instil competition into the health care system. Most of these funds are small, since the four largest cover nearly $95 \%$ of the population. The system's lack of uniformity complicates its governance.

11. A number of different ministries are involved in administering the supply of public health services, which adds to management problems. The Ministry of Health and Social Solidarity bears primary responsibility for the formulation and implementation of health policy. It allocates staff and material resources to the various public medical facilities and sets NHS regulations. Nonetheless, it shares responsibilities with other ministries. For example, responsibility for the supervision and regulation of the public insurance funds, which also administer the pension schemes, lies with the Ministry of Employment and Social Protection. This involves determining what medical benefits are covered, conditions for access to doctors and contribution rates. Concerning contribution rates, the Ministry of the Economy and Finance also intervenes, as it does in tackling the recurring deficits of the NHS and sickness insurance funds. The Ministry of Education plays a key role in determining the number of vacancies in medical schools, and the Ministry of Development sets drug prices.

\section{Box 1. The organisation of the health care system}

\section{The health care system provides universal cover}

The health care system features a mixture of public and private services and funding. The public sector comprises more than thirty sickness insurance funds, the largest of which operate their own networks of outpatient facilities, located primarily in urban areas. It also includes an integrated health care system administered directly by the State, the NHS, which delivers most hospital services as well as primary medical care in rural areas. Supplementing 
this public system is an abundant supply of private services provided by independent medical offices, diagnostic centres and hospitals.

The public system offers comprehensive medical cover to the entire population. This cover is provided through workers' compulsory affiliation to sickness funds and extends to all their dependants. The largest funds are IKA, which insures private-sector employees and their families (50.3\% of the population), OGA, which covers people working in agriculture (19.5\%), OAEE for the self-employed and OPAD for civil servants (covering respectively $12.9 \%$ and $11.7 \%) .{ }^{1}$ In addition, primary and emergency services, which are dispensed by rural health care centres and outpatient units of NHS hospitals, are open to the entire population, including illegal immigrants. The destitute also have access to NHS hospital care.

\section{Much of the funding for health care outlays is private}

Public health outlays get $48 \%$ of their funding from social security contributions and $52 \%$ from general taxation, via transfers from the State budget. The transfers are used primarily to operate rural NHS medical centres and dispensaries, and for hospital spending not covered by the fees paid by the sickness funds for their members' care. Most of the social security contributions that finance sickness funds are proportional to members' incomes and split evenly between employees and employers. ${ }^{2}$ In addition, sickness funds receive transfers to varying degrees. These are high in the case of the funds for agricultural workers and the self-employed.

Direct expenditure account for $92 \%$ of all private medical outlays by households. Supplemental private insurance plays only a minor role in Greece. It accounts for only $8 \%$ of private medical spending and covered $10 \%$ of the population in 2005 . Those figures are up from the 1980 s, when only $2 \%$ of the population had private medical insurance.

The substantial proportion of private household health spending, which accounts for roughly $40 \%$ of total outlays, does not stem from high formal patient contributions to medical costs, which are in fact rather modest. Contributions apply mainly to pharmaceuticals and vary between 0 and $25 \%$ of the costs, depending on the severity and chronic nature of the illness, as well as the patients' financial resources. Medicine dispensed in hospitals is free. A contribution is also required for hospital admissions $(€ 15)$ and for outpatient consultations at NHS hospitals (€3), except in the case of OGA members. This contribution is rarely collected, however (Mossialos et al., 2005a). Nevertheless, the use of public health services is often associated with informal payments, which are included in out-of-pocket payments.

\section{The vast majority of hospital care is public, and the supply of outpatient services is fragmented}

Hospital care is delivered by three categories of hospitals: NHS facilities, administered by the Ministry of Health; public hospitals administered by other ministries (primarily military hospitals and those operated by sickness funds); and private hospitals. Approximately $75 \%$ of hospital beds are in the public sector (67\% in the NHS) and $25 \%$ in the private sector. While NHS hospital care is accessible to the entire population free of charge, private hospitals charge fees, most of which are paid by persons covered by private insurance or by sickness funds having contractual relationships with medical service providers.

Primary health care services are dispensed by four distinct types of establishments:

- $\quad$ NHS facilities, comprising emergency services (EKAV), hospital outpatient consultations and dispensaries and medical centres in rural and semi-urban areas. These rural health care centres are administered by hospitals.

- $\quad$ Outpatient services provided by some municipalities. These services are limited in scope and cover only a narrow range of care. With regard to the city of Athens, these services are used primarily by uninsured persons and by immigrants in particular.

- $\quad$ Health care networks operated by sickness funds. Some funds have built up their own integrated networks of primary health care services. IKA, for example, has a vast network of approximately 300 polyclinics staffed by some 8000 doctors and 4000 nurses (IKA, 2005). If integrated networks of primary health care services are not available, outpatient services are delivered by NHS dispensaries and medical centres (for OGA members) or by private medical offices or diagnostic centres under contract to sickness funds.

- Medical offices, laboratories, diagnostic centres and outpatient medical consultations at private-sector hospitals. If they are not under contract to public sickness funds, these health care centres are financed by direct payments or private insurance.

\section{Status, contracts and compensation methods vary from one type of medical staff to another}

Contracts between medical service providers and public health care networks, whether run by the NHS or by an insurance fund, can take a number of different forms. In all cases, however, compensation scales for health care providers must be approved by the government (Ministry of Health or Employment). 
NHS hospitals and health care centres are generally staffed by full-time employees with civil-servant status. Rural NHS medical centres also employ interns, who are still pursuing their medical studies and are required to spend at least one year in a rural area to get their doctorate, before taking up any speciality. In the case of funds that provide their own medical services (such as IKA), the medical staff is also salaried. In contrast, private practitioners under contract are generally paid per act, according to fixed fee scales. For their part, OAEE physicians are paid by capitation. IKA also contracts with rural doctors paid by capitation for services in certain remote areas. Access to all these public services is generally free and entails no payment. However, some funds allow their members to choose their own doctors, in which case patients pay a market fee and are then reimbursed by the fund on the basis of a set scale.

Doctors employed full-time by the NHS, like those working for sickness funds, may not open private offices. NHS hospital physicians may, however, give private outpatient consultations in hospitals in the afternoon. In this case they are paid directly by patients on the basis of standard fees for services rendered, which vary between $€ 25$ and $€ 90$. Moreover, most doctors working for sickness funds have half-time contracts and are allowed to have a private practice. In this case, medical care providers are also paid at market rates (with no constraint on prices) for each service rendered. Many practitioners thus have a dual activity, working simultaneously in the public and private sectors.

1. Unemployed persons are covered by IKA, which receives public transfers for that purpose. Pensioners are covered by their original fund, except for OAEE members, who are covered by IKA when they retire.

2. The contribution rate for IKA sickness insurance is $5.10 \%$ of the salary, split equally between employers and employees. Workers belonging to OGA have a choice between seven classes of insurance, the contribution rates for which do not exceed $1.5 \%$. Similarly, OAEE members may choose among 14 classes of insurance, paying a variable standard monthly fee.

\section{There are serious gaps in statistical information}

12. The statistical system's current organisation complicates the administration of health policy for a number of reasons. First, it contributes to serious statistical gaps by making it more difficult to gather widely scattered information and to computerise the management thereof. Greece is one of the very few OECD countries that has not adopted the OECD system of health accounts. This affects not only the quality of its data but their coverage as well. ${ }^{4}$ A great deal of information that is essential to analysing how the health care system operates is missing. For instance, there are no official statistics on the breakdown of aggregate expenditure, public and private, between the various types of care - outpatient, hospital, pharmaceutical, and so on. A number of studies have highlighted this deficiency. It stems in part from methodological difficulties involving, for example, the valuation of transfers between the public and private sectors or the estimation of informal spending. Some studies have attempted to remedy this by providing estimates (Souliotis and Kyriopoulos, 2003; Siskou et al., 2008). These estimates, obtained from various sources and partial surveys, would suggest that hospital services account for over half of all public health care spending, whereas primary care accounts for the bulk of private outlays (Figure 8). However, there are no data on the resources allocated to prevention, nor on the costs of managing the system. The opacity of information also extends to the realm of waiting lists for medical services.

4. In 2008 , for example, health care spending for 2005 was revised by $10.0 \%$, to $9.1 \%$ of GDP, as compared with the series available one year earlier, and the proportion of private expenditure in aggregate outlays dropped from $57.4 \%$ to $37.1 \%$. 
Figure 8. Composition of health care spending

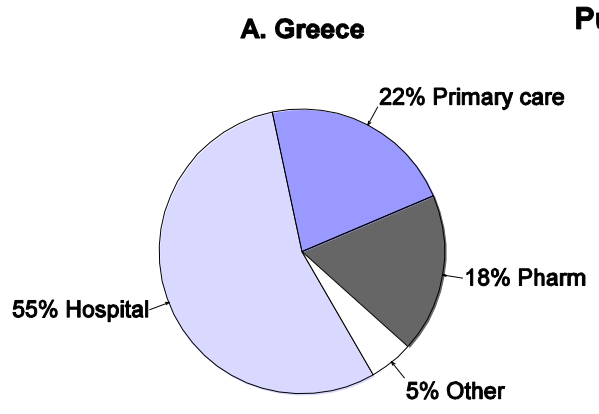

Public, 2003

B. OECD

C. Greece

Private, 2006
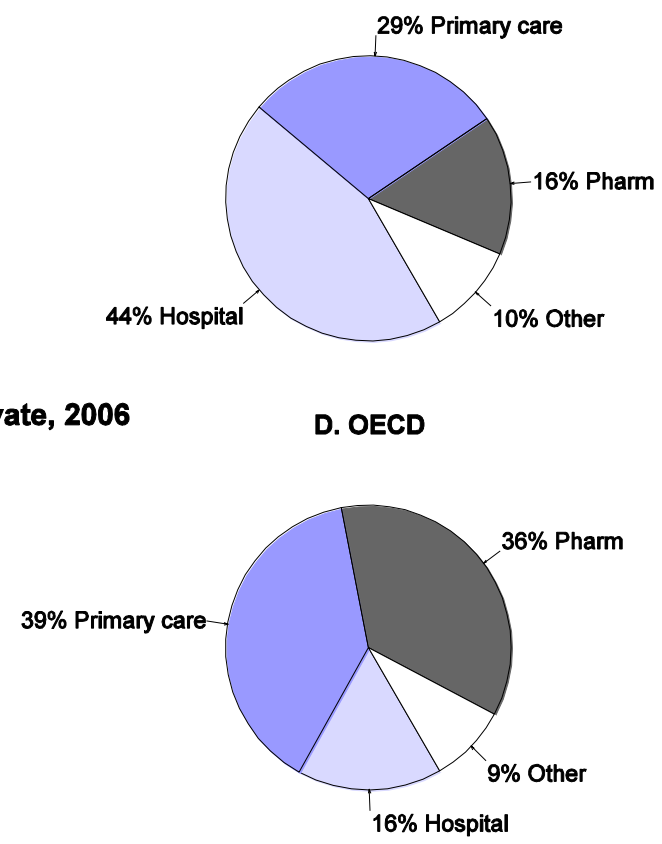

1. Greek data estimates were provided by the authorities. They are derived from specific survey and an academic analysis. They are not strictly comparable with OECD data.

Source: Data provided by the Greek authorities and OECD Health Data 2008.

\section{Medical demography is not managed satisfactorily}

13. Medical demography is not managed satisfactorily, creating imbalances in service provisions. The number of trained health care professionals depends more on the financial resources of the Ministry of Education than on concerns for balancing supply and demand of medical services (OECD, 2008a). This results in substantial imbalances. For example, the proportion of practicing doctors and dentists in the total population is very high in international comparison, while the proportion of nurses is very low (Figure 9). By some estimates, the shortage of nurses in the public sector amounts to 15000 jobs, or $40 \%$ of practicing nurses. If the gap were filled, the density of nurses in the population would rise to $4.7 \%$, which would still be well below the OECD average $(9.5 \%)$. Nurses' relatively unattractive pay constitutes a serious impediment to boosting the numbers in this field. Because of the large proportion of practicing doctors, which is aggravated by the large number of students who pursue their studies abroad, Greece is one of the few OECD countries recording net emigration of health care professionals - a loss of human capital (Figure 10). Moreover, the number of general practitioners is very low in relation to specialists, whereas it would seem preferable for public health outcomes to have many GPs rather than many specialists (Starfield, 2005). In 2006, only $2.5 \%$ of Greek physicians were GPs, or $9.5 \%$ if internists are lumped in with GPs. There are also pronounced imbalances in the geographical distribution of medical professionals. For instance, only 5\% of Greek doctors were working in NHS rural dispensaries or medical centres, whereas the rural population accounts for $25 \%$ of the total. The need for a higher density of doctors in the remote areas, especially in the islands, has been recently reinforced because of the stronger demand for care induced by the rise in illegal immigration. 
Figure 9. Human resources in the health care sector

$2006^{1}$
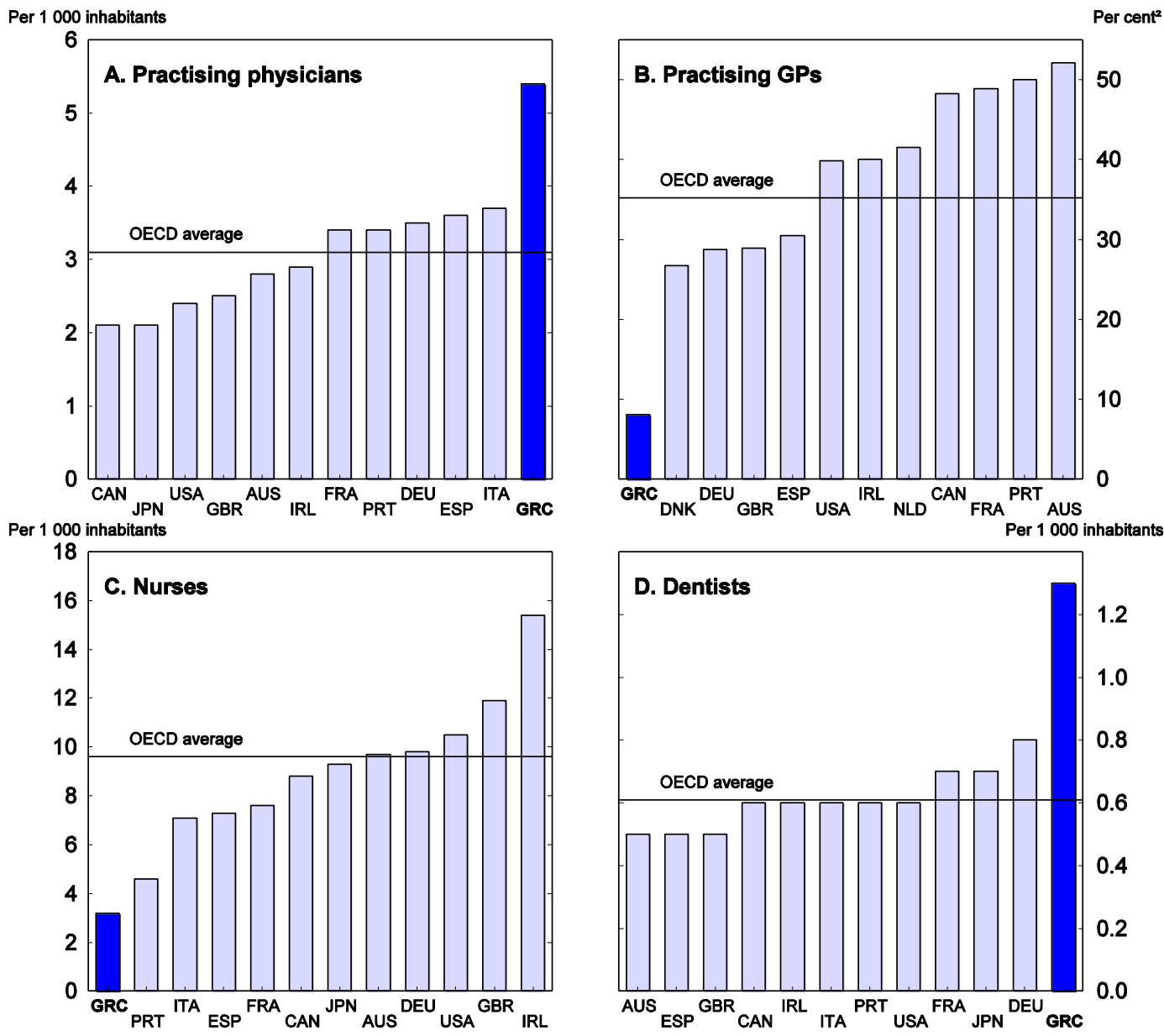

1. 2006 or latest available year.

2. Per cent of total practising GPs and practising specialists.

Source: OECD Health Data 2008.

\section{The allocation of public health resources is deficient}

14. Because the system is fragmented, funding is not pooled and the allocation of funding is generally based on neither efficiency nor fairness criteria. The authorities wield their bargaining power to a limited extent only. There is no co-ordination of procurement between insurance funds; however, the recent efforts to consolidate and rationalise the hospitals' public procurement are a step in the right direction (see below). Each insurance fund has its own administrative and financial structure. Under the circumstances, economic assessments play a very limited role in resource allocation. In this respect, the role of doctors is pre-eminent (Rovithis, 2006). Deficiencies in the realm of medical statistics are another obstacle to creating a body that could advise on effective use of resources, as is done by the National Institute for Clinical Excellence in the United Kingdom. In practice, the financial resources of hospitals are determined to a large extent by their past spending. Similar criteria would also seem to apply with regard to the allocation of central government resources amongst the regions (Mitropoulos and Sissouras, 2004). 


\section{Figure 10. Immigration and expatriation rates of doctors}

Per cent of total number of doctors, circa 2000

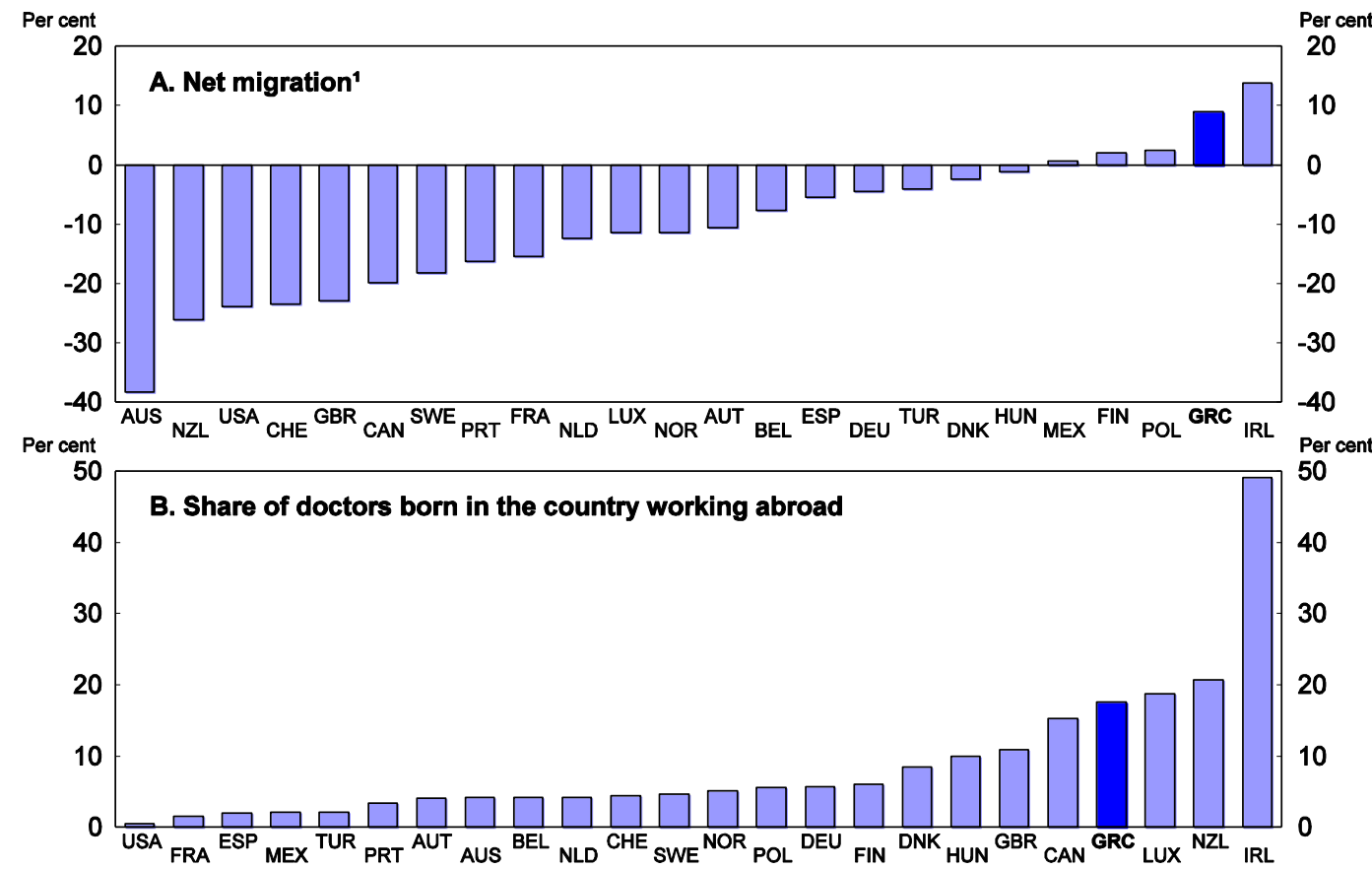

1. Doctors born in the country working abroad less foreign-born doctors expressed as a share of the total number of doctors working in the country.

Source: OECD International Migration Outlook, 2007.

15. NHS hospitals are regularly confronted by financial difficulties stemming not only from a lack of funding, but also from frequent and substantial delays in payments from insurance funds. Between 1997 and 2004, the authorities intervened on two occasions to cover hospital debt. Between May 2001 and December 2004, the amount totalled $€ 2.5$ billion (1.3\% of GDP). Since then, debt has swollen anew, to over $€ 4$ billion in the autumn of 2008 (1.6\% of GDP), and public hospitals have built up a backlog of payments, totalling another $€ 4 \frac{1}{2}$ billion, to their suppliers. Faced with the consequences of the financial crisis and the toughening conditions for access to credit, at the end of 2008, suppliers announced their intention to suspend deliveries of goods and medical equipment to NHS hospitals. In addition, the transfers regularly required to cover hospital deficits a posteriori do not provide incentives to reduce costs and enhance the efficiency of public-sector health care.

16. The health funds, which are responsible for setting the budgets for their members' primary and hospital care and pharmaceutical expenses, cannot impose binding limits on their outlays, which in practice depend on demand. The overlap between the multiple arrangements for outpatient care also leads to frequent duplication of resources and inefficiencies. Prescriptions by NHS doctors, for example, have to be validated by IKA doctors before IKA members can be reimbursed, which entails two consultations. The multiplicity of sickness funds gives rise to fairness issues as well because of qualitative differences between the cover provided by the various public health schemes, which are not necessarily reflected in the respective contribution rates. Trade unions representing the most generous funds have in the past systematically opposed any attempt to consolidate the funds (Davaki and Mossialos, 2005). These particular insurance funds (OPAD, OAEE and the funds serving the banking sector and public services, which are considered "noble funds"), for example, offer access to private hospitals and freedom to choose one's own doctor for primary care, which neither IKA nor OGA offers. In contrast, the NHS primary care facilities open to OGA members are short on equipment and personnel or are staffed by interns completing 
their training and having limited clinical experience. This impairs the services they deliver (Tountas et al., 2005).

17. Too few resources seem to be allocated to prevention, which hampers the efficiency of the system. The population's immunisation rate would suggest that Greece lags behind in this area. While the vaccination rate has risen sharply over the past 20 years, it is still lower than in most other OECD countries. For instance, $12 \%$ of children have not been immunised against diphtheria, tetanus, whooping cough (DTP3) or measles (Figure 11). Another key component of prevention involves the promotion of healthy lifestyles, with respect to eating habits and smoking in particular. Among OECD countries for which data are available, Greece holds the record for smoking and ranks fifth in calorie consumption per capita, after the United States, Portugal, Ireland and Austria. While much of the Greek population still seems to adhere to a Mediterranean diet, ${ }^{5}$ a growing proportion, many of whom are young, tends to adopt eating habits involving substantial intake of sugar and fats (Costacou et al., 2003). These trends over the past two decades have had detrimental effects on public health. For example, illnesses of the circulatory system, for which smoking is another contributing factor, represent a relatively greater cause of mortality in Greece than in the OECD area as a whole, with $47 \%$ of deaths being related to cardio-vascular problems (Figure 12). ${ }^{6}$ Moreover, despite recent increases, tobacco prices are still low. Smoking could be cut back by raising the excise tax on these products, as shown by the experience of other OECD countries. A more active prevention programme would probably have beneficial effects on health outcomes. Here, the efforts undertaken since 2005 to promote health should be stepped up. ${ }^{7}$

\section{Figure 11. Children immunised in OECD countries}

Per cent of children immunised, $2006^{1}$
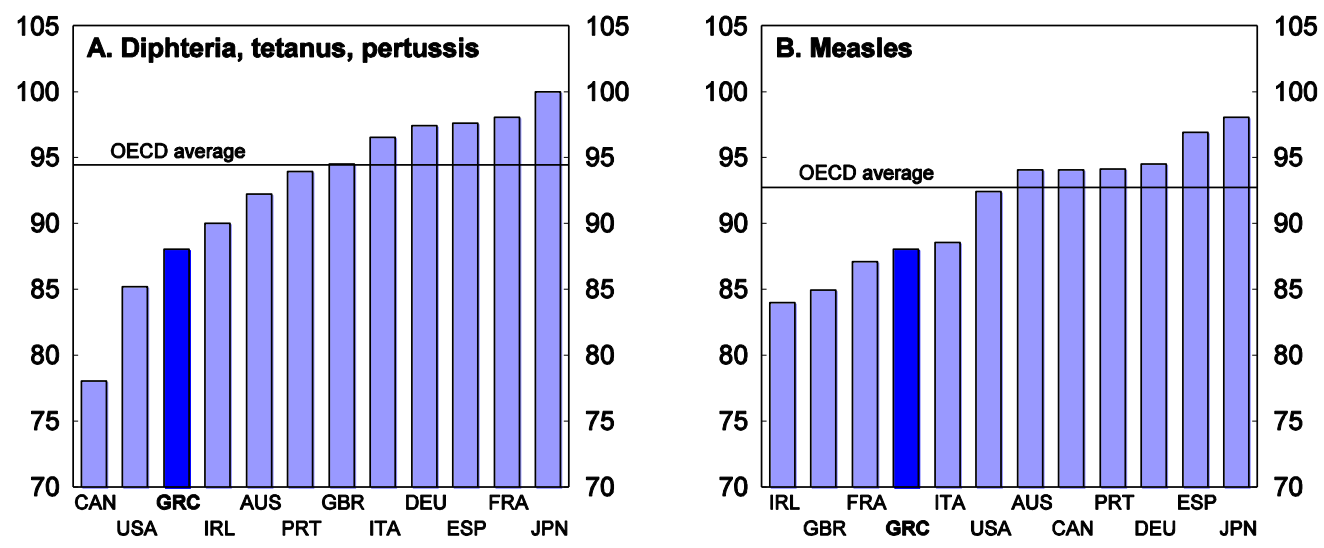

1. 2006 or latest year available.

Source: OECD Health Data 2008.

5. A Mediterranean diet features substantial consumption of fruit, vegetables and olive oil and only small quantities of meat, poultry and saturated fats. It is associated with lower mortality from heart disease and cancer (Trichopoulou et al., 2003).

6. International comparisons highlighting the relatively high mortality, but not the frequency, of cardiovascular diseases in Greece could also indicate that these pathologies are treated less well than they are in the other countries.

7. A consultation process is underway to develop a national public health action plan extending until 2013. The emphasis is on five major threats to health: cancer, AIDS, rare diseases, drug use and eating disorders. 
Figure 12. Calorie intake, tobacco consumption and health risks
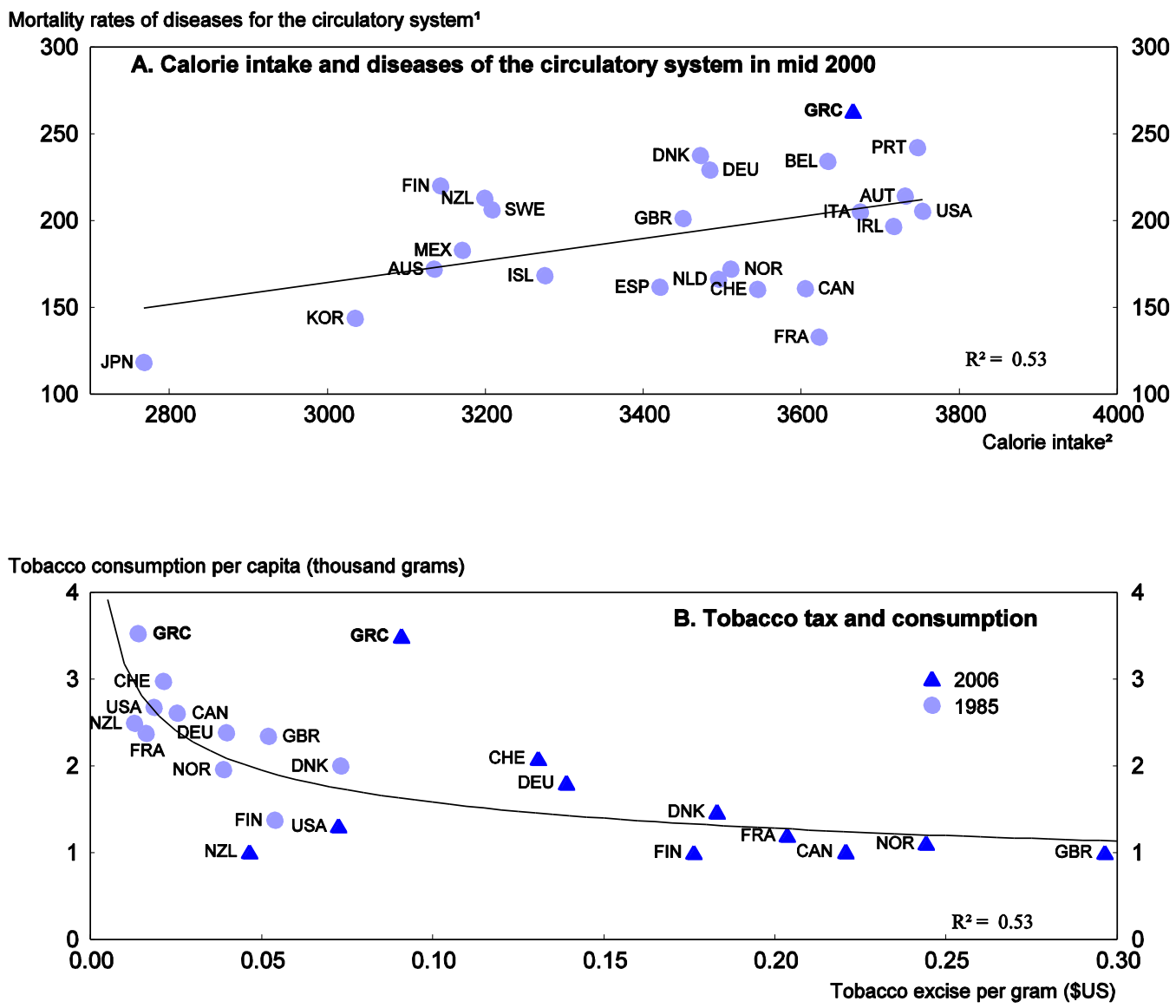

1. Deaths per 100000 inhabitants, 2006 or latest available year.

2. Per capita/days, 2003.

Source: OECD Health Data 2008.

\section{Control over public health spending is steeped in bureaucracy}

18. The way the control of public health spending is wielded creates inefficiencies. Analysts has pointed out that cost control by the Ministry of Health is too bureaucratic and too centralised (WHO, 1996; Ballas and Tsoukas, 2004; Mossialos et al., 2005a). The Ministry sets most of the fees and wages for public-sector medical services and determines staffing levels at rural hospitals and health care centres, along with the mix of specialities. In tandem with the Ministry of Economy and Finance, it also sets these fees for the civil service sickness fund (OPAD). Fees charged by the other funds require approval by the Ministry of Employment. Despite the glut of physicians, the NHS suffers from labour shortages in some fields and some locations, due in part to hiring restrictions imposed for budgetary reasons, and from the weakness of incentives for doctors to go to remote areas. Moreover, the financial administration of hospitals and health care centres is strictly regulated, and the Ministry gives hospitals very little leeway in management and organisation, which, combined with the fact that the government takes on deficits ex post, is hardly conducive to efficiency. The creation of administrative health care regions (DYPEs) in 2001 was meant to decentralise some of the powers of the Ministry of Health so as to improve the allocation of human resources between departments and hospitals within a given region. This decentralisation process, which eliminated the rigidities caused by the fact that staff report directly to hospital departments, had little 
success, however. Despite the reform, DYPEs have not enjoyed real independence that would enable them to improve management. Their governing bodies and directors-general are appointed by the Minister of Health (Economic and Social Council of Greece, 2005a). Regional health authorities, which are responsible for co-ordinating resource allocation within their geographic areas, also lack the means to finance substantial capital investment or to recruit practitioners, and all their financial transactions have to be approved by the Ministry (WHO/EURO, 2006). DYPEs, the number of which was reduced from 17 to 7 in 2006 to achieve economies of scale, ${ }^{8}$ have proved to be yet another bureaucracy and, above all play an advisory role for the Ministry of Health and supervise implementation of its policy (Economic and Social Council of Greece, 2005).

19. The low level of prices of public-sector medical services and salary scales for NHS doctors and those working for sickness funds creates large private payments. There is no differentiation between hospital doctor salaries according to speciality (Mossialos et al., 2005a). Compensation, which is set via mechanisms of indexation to historical costs, is a recurring source of conflict between the medical profession and the government. To circumvent the pay limits for NHS doctors, doctors are paid for fictitious overtime. Even so, by international standards, the average compensation level per doctor would seem rather low, but another partial explanation of this could be the large number of doctors (Figure 13). Similarly, the sickness funds' reimbursements for medical services are also set at levels far below market prices in the private sector. In the case of pap smears (to screen for uterine cancer), for example, the gap between reimbursements and market prices is a factor of one to ten. Sickness funds also pay hospitals on the basis of a per diem that represents only 20 to $30 \%$ of the total daily cost of services. To compensate, NHS hospitals get roughly $65 \%$ of their funding from the state budget and about $35 \%$ from payments by sickness funds and insured patients' direct contributions to costs.

Figure 13. Compensation level of practising specialists

20061

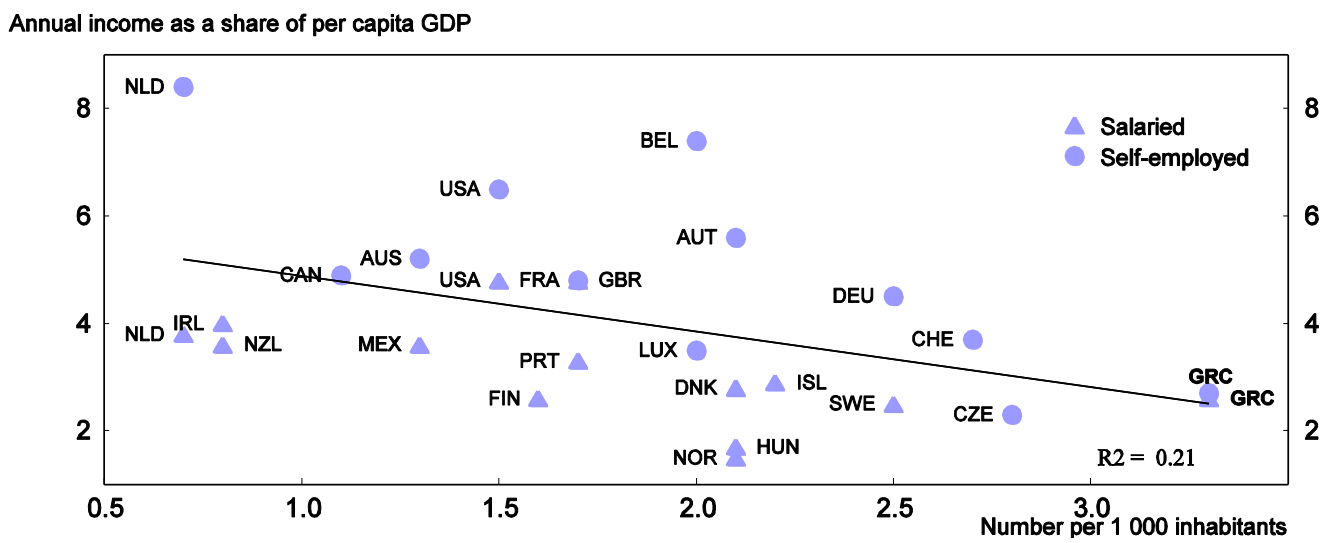

1. Or latest available year.

Source: OECD Health Data 2008.

20. The relatively low prices paid by sickness funds for public hospital services create distortions and prompt them to make excessive use of hospital care as opposed to outpatient care, thus overloading hospital capacity. The fee structure of sickness funds' reimbursements for hospital services is shaped more by the desire to control public spending than by concerns for the system's efficiency. It eases the financial burden on sickness funds and trims non-wage labour costs, which are high in Greece and conducive to undeclared work. This leads to hospital outlays as a percentage of aggregate health care costs that are

8. The scaling back of the number of DYPEs could reduce their operating costs from $€ 50$ to 15 million. Also, 400 of the 750 persons employed by DYPEs will be transferred to hospitals suffering staff shortages. 
significantly higher than the OECD average (Figure 8). This situation also reflects the authorities' stated desire to provide a primarily public supply of hospital care, even since the ban on building private facilities was lifted in 1992. Underfunding of hospitals by the sickness funds makes it difficult to sustain a viable supply of private services without additional financing. As a result, the private sector's share of total hospital beds dropped from $42 \%$ in 1980 to $25 \%$ in 2006, and less than $20 \%$ of admissions are to private hospitals.

\section{Deficiencies in the public system boost private spending...}

21. The rapid expansion of private medical spending (Figure 14), despite the numerous impediments imposed, for example, in the realm of hospital care, bears witness to the population's dissatisfaction with the public health care system (Tountas et al., 2005; Siskou et al., 2008). This stems from the poor quality of food and accommodation at hospitals and, more fundamentally, the shortage of hospital facilities in certain areas and long waiting lists for certain specialities, such as cardiac surgery and oncology. In contrast to the procedure at private hospitals, it is not possible to choose one's own doctor. As a result, $64 \%$ of private hospital care consists of surgical acts, while the proportion is $44 \%$ in the public sector.

Figure 14. Health expenditure growth

Per capita, ${ }^{1} 1990-2006$
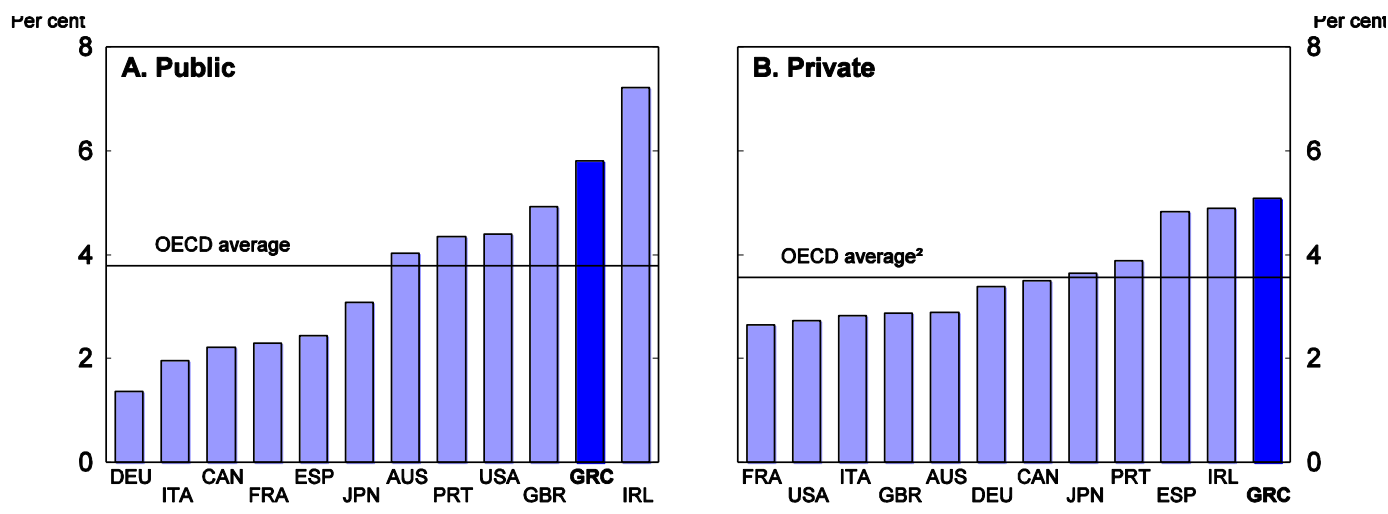

1. 2000 GDP price.

2. Less Czech Republic, Hungary, Poland and Slovakia.

Source: OECD Health Data 2008.

22. Dissatisfaction with the public health care system is most intense for primary care. The sector suffers from a lack of credibility: after consulting a doctor in the public sector, patients frequently turn to the private sector for a second opinion (Mossialos et al., 2005a). It is thought that about 50\% of aggregate primary care outlays are financed directly by households, whereas the corresponding proportion for hospital care and pharmaceuticals does not exceed 30\% (Figure 15). This stems not only from the public sector's incomplete cover for certain types of care, such as dentistry (see below), but also from a shortage of technical equipment (MRI, CT scanning, etc.) which forces sickness funds to resort to the private sector to meet many of their requirements for diagnostic services. Following the ban on the development of private hospital services until the early 1990s, rapid growth was observed in private laboratories and private diagnostic centres, which made substantial investments (Tountas et al., 2005). Moreover, in 2005, Greece's overall medical equipment rate (CT scans, MRI) was well above the OECD average, despite the equipment shortages in the public sector (Figure 16). 
Figure 15. Share of health care financed by public expenditure ${ }^{1}$ 2006
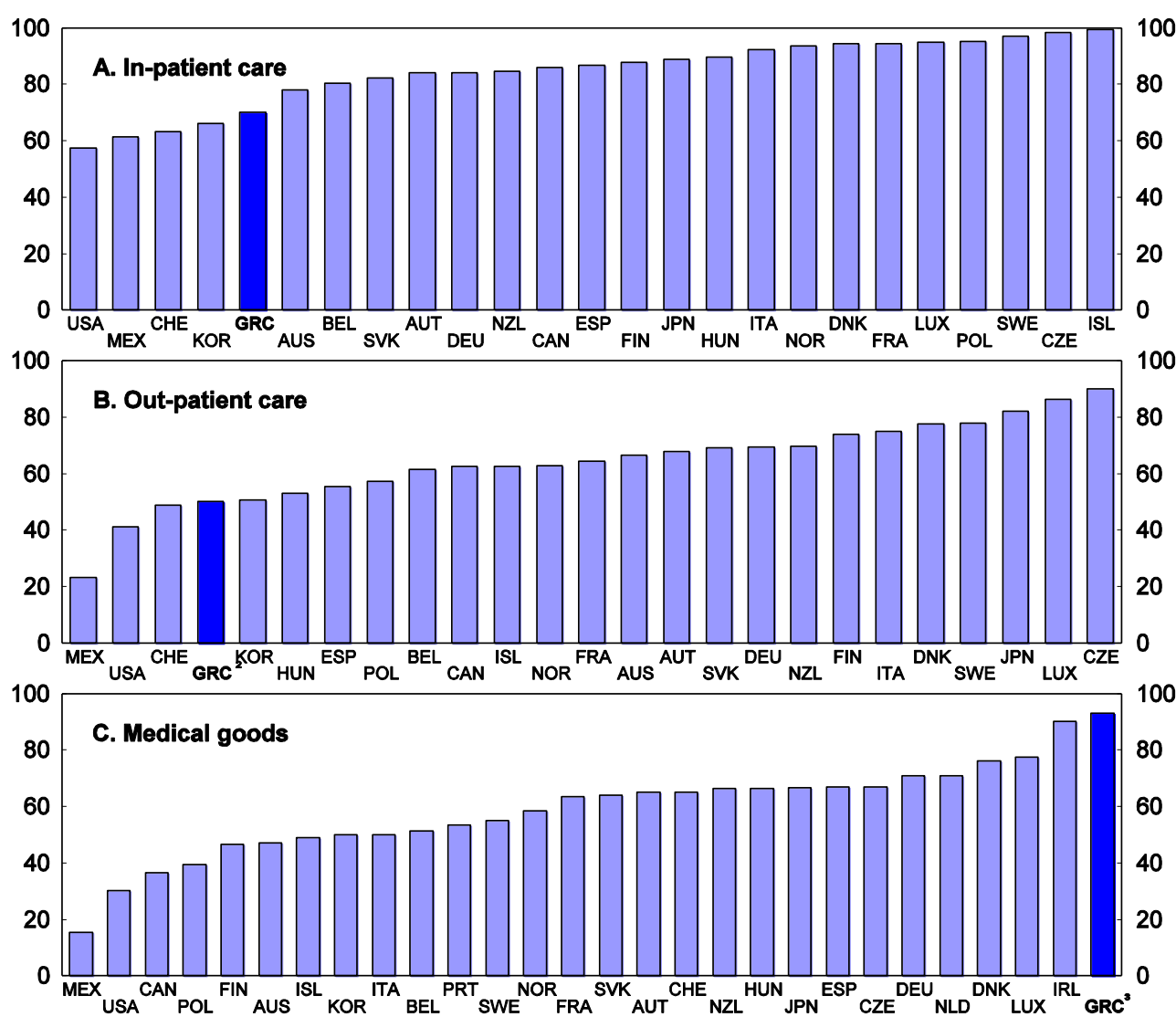

1. Under the SHA classification the important criterion is the mandatory nature of social insurance. Compulsory insurance administered by private companies is classified under the public sector. This type of insurance is particularly important in the Netherlands and in Switzerland.

2. Medical services.

3. Pharmaceuticals and other medical non-durables.

Source: Health database 2008; Siskou O, et al., Private health expenditure in the Greek health care system: Where truth ends and the myth begins, Health Policy (2008), doi:10.1016/j.healthpol.2008.03.016.

Figure 16. Medical technology equipment

Unit per million inhabitants, $2006^{1}$
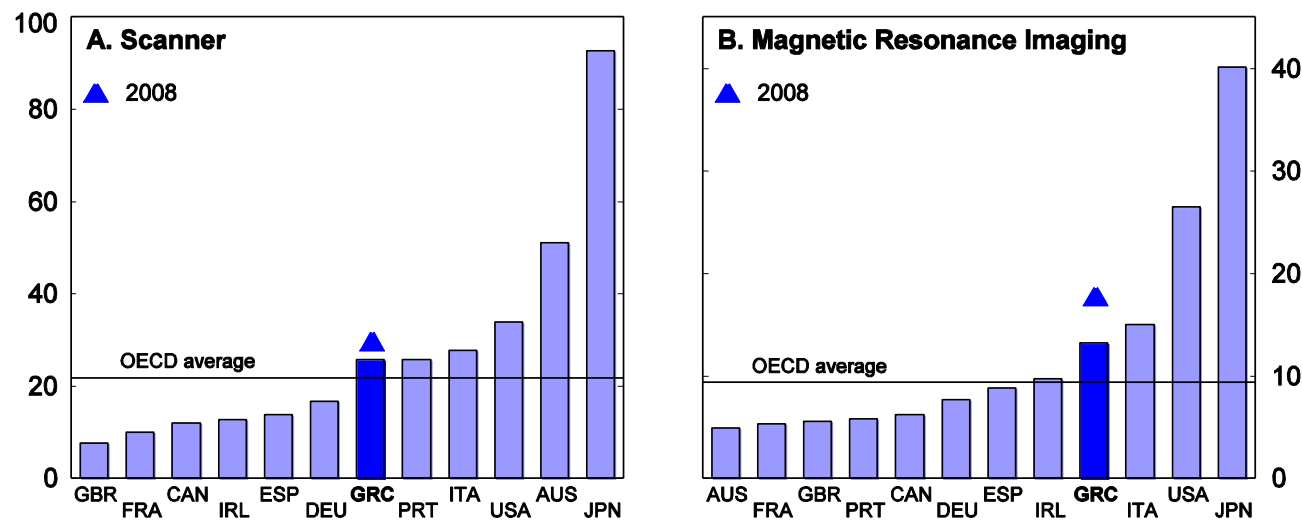

1. Or latest year available.

Source: OECD Health Data 2008. 
23. Supervision of diagnostic services outsourced to the private sector must be improved, however, to reduce waste. Sickness funds complain regularly about the billing methods of private hospitals, which enable them to include supplemental medical services, the need for which is in some cases doubtful (Tountas et al., 2005). Sickness funds lack bargaining power and meaningful oversight capability, as clinical protocols and payment according to diagnostic categories are absent. This is conducive to overconsumption of care, especially given the scant control over doctors' prescriptions in this area, and it cannot be ruled out that doctors enjoy some informal financial incentives provided by private diagnostic centres (Mossialos et al., 2005a).

24. Another factor that has contributed to the expansion of the private sector is the large number of trained doctors whom public-sector hiring restrictions encourage to set up in private practice. Many of these physicians practice simultaneously in both sectors. Indeed, constraints on pay rises for medical staff in the public sector have prompted the government to authorise dual practice for doctors employed halftime by sickness funds. But these doctors use their public consultations to build up a private clientele and boost their income, to compensate for the low level of salaries in the public sector and the wide gap between official reimbursement rates for medical acts and market prices. Complaining about their heavy workload and limited time to devote to each patient, these practitioners often refer public patients to their own private consultations.

\section{...which poses problems of fairness...}

25. The high level of private expenditure is one reason why modest-income segments of the population seek dental care less frequently than affluent households, the difference in Greece being wider than for the OECD average (Van Doorslaer et al., 2004). According to available estimates, dental care, which is covered poorly by most public health care systems, accounts for an especially large proportion of private medical expenditure in Greece (31\%), or nearly $1 \%$ of GDP, versus $0.7 \%$ of GDP in the United States and 0.3\% of GDP in the European countries (Siskou et al., 2008). More generally, the tight budget constraint for modest-income households limits their spending on private primary care. According to Huisman et al. (2003), Greece is also one of the European countries in which the impact of income or educational inequalities on the health of the elderly is greatest. Moreover, the use of many health care services may be affected to a significant extent by an income effect, which may pose access problems for families with scant resources (Mergoupis, 2003). This income effect, which may also reflect differences in education or a lack of information for certain social groups, is more pronounced than in Italy. It is also greater in the case of services specially aimed at women, which raises a potential problem of gender inequality in access to care. ${ }^{9}$

26. Paradoxically, visits to private doctors seem more frequent in rural areas than in urban ones (Siskou et al., 2008), although regional disparities in the allocation of health care infrastructure would not appear exceptional in Greece as compared with other OECD countries (OECD, 2007). This would seem to reveal the existence of gaps in the supply of some medical services, which in some cases force people who are not very well off to avail themselves of private services. These outcomes are especially significant insofar as education and income effects would presumably be greater in urban environments. Similarly, households headed by a person with a low level of education are relatively more likely to consult private

9. Huisman et al. (2003) evaluate the use of 17 health care services that are standardised, have limited cost and are important for prevention. Eleven of these services are aimed at the entire population (hospital stays, medical consultations, eye tests, hearing tests, blood and urine tests, screening for diabetes, cholesterol and cancer, $\mathrm{x}$-rays and heart check-ups), and seven specifically target women (mammography, palpation of the breasts, gynaecological and ovarian examinations, pap smears and osteoporosis screening). Four of these services (hospital stays, medical consultations, hearing tests and osteoporosis screening) feature nonsignificant income elasticities. Among the other services, which feature significant and positive income elasticities, those elasticities are $50 \%$ higher on average with respect to services aimed at women. 
surgeons, which might stem from greater exposure to the risk of accidents requiring emergency care that cannot be delivered quickly enough in the public sector. Because of this forced recourse to private medical services, $2.4 \%$ of Greek households are believed to spend over $40 \%$ of their disposable income on health care, because of unexpected medical expenses (Economou et al., 2004). This proportion is high by international standards, since the corresponding average for twenty OECD countries for which the information is available is $0.6 \%$, and in ten of those countries the proportion is no greater than $0.2 \%$ (Xu et al., 2003).

\section{...and contributes to the development of informal payments}

27. The private outlays of households also include a significant proportion of informal payments. As noted by Souliotis and Kyriopoulos (2003), no realistic analysis can disregard this phenomenon, even if the extent of it is difficult to measure. For example, Kyriopoulos and Karalis (1997) have measured the share of the underground economy in the health sector at $13.4 \%$ of aggregate medical expenditure. More recently, Kyriopoulos (2004) revised this estimate upwards to $17 \%$ of total expenditure on health. These estimates are not out of line with the relatively high proportion (between 20 and 25\% of GDP) generally attributed to unreported activity in the economy as a whole (Chapter 2). Siskou et al. (2008) arrived at an estimate of informal outlays in the hospital sector, amounting to only some $20 \%$ of private household spending in the sector, or as much as their formal contributions to hospital costs.

28. Informal transactions are typically direct payments by patients for services to which they are entitled free of charge. Such payments generally take the form of "gratuities" or "bribes" (fakellaki in Greek, meaning "small envelopes") paid during consultations at doctors' offices or for hospital services. A recent survey, based on a sample of 4738 individual observations, concluded that $36 \%$ of the people treated in public hospitals had made at least one informal payment (Liaropoulos et al., 2008). For 19\%, these payments were additional fees exacted by salaried doctors, while for $17 \%$ they were "voluntary gratuities". The probability of making such payments was $72 \%$ greater for people wishing to avoid a waiting list as compared to those following standard admission procedures and $137 \%$ greater for patients requiring surgery. The median amount of payments was $€ 300$, or double the amount of monthly household spending on private health care (or $15 \%$ of their aggregate monthly outlays), and $€ 200$ in the case of gratuities. Nurses also receive gratuities, but of a lesser amount ( $€ 25$ to $€ 35$ ). This behaviour is encouraged by low pay in the public sector. As a result, it has been estimated that, on average, patients pay additional fees of approximately $€ 5300$ for heart operations for which the reimbursement is $€ 8800$ (Siskou et al., 2008).

29. Such practices constitute an obvious sign of the population's lack of faith in the public health care system. On the demand side, these transactions, which are sometimes explained by sociological factors like "the tipping culture" the system, eliminate waiting lists or improve the quality of care. On the supply side, informal payments highlight the absence of effective supervisory mechanisms which allows care providers to exploit their market power for private gain.

30. These direct payments exacerbate the health system's problems. They skew resource allocation towards those who are able to pay, and away from those with the greatest need, who will have to wait longer and will not enjoy an equivalent quality of service. Informal payments also tend to be regressive: while poor individuals may pay less than the rich, their contributions represent a greater proportion of their incomes, and the phenomenon is rectified only very imperfectly by the positive discrimination in which

10. This is probably one reason for the limited growth of private insurance, the intervention of a third party to make such payments being perceived as a dilution of the close relationship that patients wish to establish with their doctors. 
doctors sometimes engage to favour modest-income patients on the basis of subjective and vague criteria (Allin et al., 2005). Moreover, these practices may encourage unprofessional conduct such as rent-seeking by medical personnel. This impairs transparency and fosters corruption through the use of public facilities for private ends and tax evasion. In addition, by appropriating all of the payments made by patients, doctors reduce the resources available for improving how the health care system works.

\section{The quality and efficiency of public health care services need to be improved}

\section{The shortcomings of public primary health care services have to be remedied}

31. Apart from the quality problems affecting public primary care services, microeconomic studies show that there is wide scope for improving how resources are deployed. According to Kontodimopoulos et al. (2007), for example, there is an average 15\% technical efficiency differential between the primary care centres managed by IKA and those of the National Health System (NHS). However, efficiency problems also affect the medical centres of each network. ${ }^{11}$ These differentials demonstrate the lack of incentives for care providers to improve their services. The current policy of limiting salary levels and reimbursements of fees by the public sector, combined with the lack of control over the number of practitioners, can lead to opportunistic behaviour. The many physicians working part-time for IKA often put in fewer hours than their contracts call for, and they minimise the effort they devote to the public sector to promote their private practice (Mossialos et al., 2005a). Moreover, if doctors are barred from private practice, in many cases they receive informal payments.

32. Enhancing incentives poses difficult problems, however. One possibility might be to bar dual practice. The risk here, however, is that it might trigger an increase in informal payments if compensation stays low. Even so, there is no guarantee that higher pay would succeed; the sharp pay rises (of up to 250\%) granted to NHS doctors in 1985 to put an end to informal payments did not have the expected results (Mossialos et al., 2005a). ${ }^{12}$ Changes in how compensation is paid would probably be more effective in bolstering the incentives of public care providers to improve their services. Informal transactions, which expanded under the impetus of market forces, actually introduce a form of fee-for-service payment to obtain higher-quality care. But shifting to such a system of payment would pose difficulties for public spending control. The level of expenditure per capita at OPAD (which covers civil servants), where this form of compensation is in effect, is in fact three times higher than at OAEE, where doctors are paid by capitation, and double that of IKA, whose physicians are salaried. Fee-for service, which also applies to private service providers working for sickness funds, encourages physicians to induce additional demand, since they are in a better position to increase the volume of acts to offset low fees per consultation. To avoid such a problem, one solution might be a hybrid system combining capitation payments and payments per act. This would foster competition among doctors more than the salaries used at IKA or in the NHS, while at the same time allowing a certain degree of control over spending (Simoens and Hurst, 2006).

33. Another option for reconciling control over public spending and improvements to primary care would be to establish a gate-way system. In this way, patients' demand could be met more effectively, following an assessment of their needs, unnecessary technical examinations could be avoided, and health care would become more cost-effective (OECD, 2004). Such an approach would in fact help take better

11. The efficiency of care centres is measured by Kontodimopoulos et al. (2007) using a DEA analysis in which inputs include medical, nursing and administrative staff and outputs are quantified by the number of consultations and medical examinations performed. Using the same methodology, Zavras et al. (2002) compare the efficiency of 133 IKA primary care units and highlight that the best results are achieved by medium-sized centres (covering a population of 10000 to 50000 people) that are equipped with the infrastructure needed to perform laboratory and radiological examinations.

12. Examples in other countries show that it is often the highest-paid doctors who engage in such practices, which probably reflects their power (Allin et al., 2005). 
account of people's social, family and cultural particularities rather than focusing on pathologies associated with particular fields of medicine. It would also result in a better balance between preventive and curative medicine, improved follow-up and enhanced co-ordination of care for persons afflicted with chronic illnesses, whose ranks are expected to increase due to population ageing (WHO, 2008; Saltman et al., 2008). As a growing body of empirical work suggests, health systems that provide comprehensive, continuous general care accessible to the entire population, and which co-ordinate care of a more specialised nature, are generally associated with better health indicators and lower costs for all medical services (Starfield and Shi, 2002; Macinko et al., 2003; Starfield et al., 2005). But to set up such a system, which has been considered in the past, runs into the problem that the proportion of general practitioners is very low. It also prompts reticence because it could restrict choice. The success of such a system would also hinge on the incentives for GPs to provide high-quality diagnoses (Garcias-Mariñoso and Jalovac, 2003). In the case of Greece, this would probably entail increasing the compensation of GPs and changing the way they are paid, inter alia to reinforce their incentive to locate outside of urban areas.

34. More generally, the continuity of the supply of health care should be improved, and there should be greater supervision of medical practices. There are no portable individual health care records nor any mechanisms for organising and co-ordinating medical files amongst health care providers, even if each of them is required to keep a written record of patient files. Legislation adopted in 2004 called for the introduction of an electronic medical file for each patient, but the files were never issued. Lack of this information can lead to unnecessary duplication of acts, examinations and prescriptions. Nor had there been any mechanisms for supervising or assessing doctors' practices that could detect any "excessive" behaviour and harmonise prescription habits on the basis of diagnostic protocols factoring in, inter alia, economic evaluations. ${ }^{13}$ However, the new mechanism for monitoring prescriptions for drugs that has been launched recently (see below) aims to address some of these shortcomings. Greece had the highest rate of antibiotics prescriptions of 13 OECD countries at the end of the 1990s (Mossialos et al., 2005a), and the proportion of Caesarean deliveries, which seems singularly high, would not appear to reflect just medical needs. The 2002 Caesarean birth rate in greater Athens, estimated at 53\% for private hospitals and $42 \%$ for public ones, far exceeded the average for the other OECD countries (of roughly 25\%). Analysis of the reasons for this high incidence validates the hypothesis of induced demand stemming from a financial and comfort-related motivation (Mossialos et al., 2005b).

35. To improve operations in the primary care sector and reduce its fragmentation, the authorities are preparing a draft legislation to establish a system of referring physicians with free choice of personal doctor. The bill, which is to be submitted to parliament during the summer 2009, would establish a network of both public and private primary care providers and help to ensure a better coordination between them. It also calls for the introduction of medical protocols and procedures as basis for fees and benefits. To rein in the growth of public health spending, each patient will be given an individual health account with a yearly expenditure ceiling. Spending above this limit will require an authorisation to justify the allocation of more resources. To reduce the existing inequality of access to the primary health care services across the insurance sickness funds, the same minimum package of services will have to be provided by all funds. These provisions will be initially applied to the fund of public sector employees (OPAD), with the other insurance funds having the possibility to participate to this project on a voluntary basis over the next five years.

36. The reforms considered in this bill appear to be going in the right direction, although many points have still to be clarified to ensure its effective application: What kind of incentives will be put in place to favour the development of a referral system? How will the diffusion of medical protocols and procedures be ensured among the physicians? How will the individual health accounts be managed in practice? On

13. Nor have any random audits of the insured's medical consumption behaviour been introduced, as they have in some other countries (such as France), to limit "medical nomadism". 
what basis will the expenditure ceiling be set? Should specific provisions be adopted to prevent healthy people to consider this budget as an "entitlement" and to consume more? How can excessive increase in management cost of this system be avoided?

\section{Hospital funding should be rationalised and its management professionalised}

37. Efforts have been made in recent years to make hospitals more efficient. Average hospital stays and the number of acute-care beds per thousand population have been scaled back, occupancy rates have increased and these indicators were close to the OECD average in the mid-2000s. Despite these improvements, which in part reflect better clinical practices, efficiency gains of some 20 to $30 \%$ of hospital expenditure may be feasible (Aletras, 1999; Giokas, 2001).

38. The need for further efficiency gains is especially great as hospitals are subject to strong demand pressures. Given the problems affecting the outpatient care system, external consultations at NHS hospitals are used extensively as an initial contact point for primary care. These pressures, which exist with respect to care that requires hospitalisation as well, are especially perceptible for nursing services. The lack of resources in this area often drives patients to resort to private health care aides during their stay in hospital. ${ }^{14}$ In addition, waiting lists exist. Despite the lack of statistics in this area, most observers acknowledge the existence of problems associated with certain types of care. According to the daily newspaper $\mathrm{Ta} \mathrm{Nea}$, the wait is six months for surgery in Athens hospitals, for example, five months for an outpatient neurological consultation and approximately three months for radiotherapy or an operation to treat a malignant tumour (Tanner, 2008).

39. A number of factors limit the efficiency of the hospitals. One is the NHS staff's status as relatively poorly paid civil servants. The biggest problem, however, probably has to do with the financial management of hospitals. Accounting is on a cash rather than transaction basis, thus making it difficult to assess the financial position of hospitals. Indeed, the system cannot determine the relationship between financial resources committed and how they are used, which precludes any assessment of the efficiency of resource allocation in absence of cost accounting (Ballas and Tsoukas, 2004). These defects, which have been acknowledged for many years, will soon be resolved, since all NHS hospitals would report their financial statements with a new accounting system by 2010. Already, 100 of the 130 hospitals have complied. The use of a double-entry accounting system will also facilitate data collections needed to improve the quality of Greek health statistics.

40. According to Ballas and Tsoukas (2004), one of the reasons why not enough attention is paid to developing robust management tools is a lack of professionalism in the administration of the NHS. NHS hospital directors are appointed on the basis of political criteria, as are the presidents of administrative health regions, and only a minority of these have managerial skills. The 2001 reform, which decentralised the health system into regions, had revamped the system of hospital governance by instituting executive boards headed by managers appointed on the basis of their professional qualifications to five-year terms. However, that reform was called into question in 2005, in part because of opposition from the medical profession to what they deemed illegitimate "technocratic" management of health care (Rovithis, 2006).

14. The frequency of use of such services and the induced private expenditure (estimated at $4 \%$ of private hospital care) would not seem correlated with socioeconomic variables. The practice would therefore seem fairly widespread throughout the hospital system. The services of these private health care aides, in many cases under-qualified, are arranged for outside the normal procedures for nursing care (Siskou et al., 2008). 
41. Recent initiatives have focused on improving the management of public procurement. Under the 2007 reform, which is currently being implemented, procurement will be centralised and managed by a specialised committee. Until now, each hospital had for the most part purchased its medical products. The Ministry of Health had of course established a list of medical goods and equipment for which purchases required its prior approval. Frequently, however, contract award procedures were disregarded because of the non-exhaustive nature of the list, or on the pretext that it was difficult to foresee needs for certain medical devices, such as pacemakers, implants or artificial kidneys. The reform is therefore welcome as a means to rationalise the management of public procurement, improve transparency and achieve economies of scale.

42. Since 2005 the authorities have also expanded options for partnerships with the private sector in the management of public hospitals. This has paved the way for the construction, financing and management of auxiliary services (such as catering, security and maintenance), as well as the supply and upkeep of clinical and support equipment in four hospitals since 2007. Public/private partnerships (PPPs) can be beneficial if they are approached with a view to raising efficiency and control of cost and not merely by a desire to take the financing of capital investment off the public accounts. Well-designed projects can allow the public sector to benefit from private-sector know-how, but international experience also shows that the use of PPPs can prove costly for public finances if projects are managed poorly (OECD, 2008b). The use of such instruments thus demands great caution and a transparent evaluation of projects. It is also important to clearly specify who bears the financial risks attached to these projects.

\section{Better control over pharmaceutical expenditures is possible}

43. As in many other countries, the growth of spending on drugs has outpaced that of other medical outlays. While this trend increase was more pronounced in Greece (Figure 17), the share of drug consumption, which rose to about $18 \%$ of aggregate health outlays in the mid-2000s, was close to the OECD average. Slowing the cost escalation has run up against a number of difficulties. The control of drug price increases has had little impact on rising pharmaceutical outlays, ${ }^{15}$ as restrictions have been circumvented by the introduction of new, more expensive products (Mossialos et al., 2005a). To limit the rise in expenditure, the authorities also introduced a positive list of reimbursed products in 1998, which remained in effect until 2006. This list was updated regularly by a unit of the Ministry of Health, the National Organisation for Medicines (EOF), which evaluates drugs on the basis of therapeutic effectiveness, product safety, daily treatment cost and reimbursement in other EU Member States. However, this policy seems to have had only a limited and temporary effect (Contiades et al., 2007 and Yfantopoulos, 2008), especially because physicians frequently exercised their right to authorise the reimbursement of products not on the list.

15. Between 1990 and 2008, the increase in drug prices as recorded in the consumer price index was below the rise of the index as a whole. 


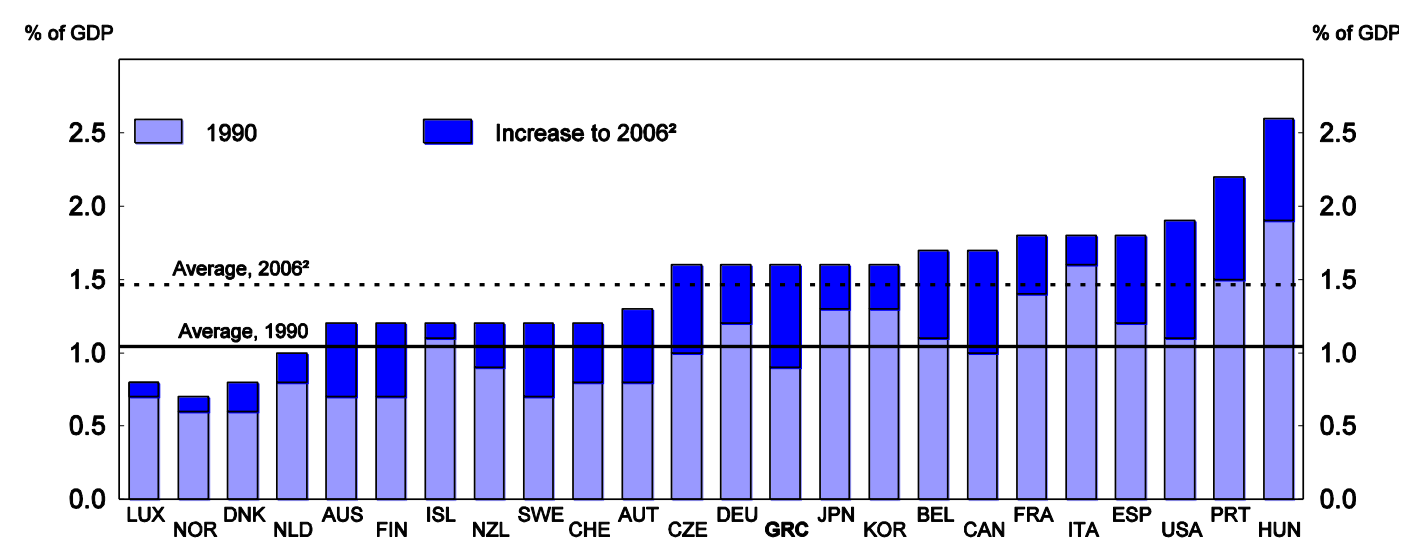

1. And other medical non-durables.

2. Or latest year available.

Source: OECD Health Data 2008.

44. In 2006, the government adopted new rules for setting drug prices and reimbursements. The list of reimbursable drugs was eliminated, and a new system of reference prices, determined on the basis of the lowest prices in the European Union countries plus Switzerland, came into effect. The new regulations also introduced a mechanism whereby pharmaceutical companies were to reimburse health funds for any excess of the price of a reimbursed treatment over the reference price set by a committee established for that purpose. The mechanism was never implemented, however, because of opposition and legal challenges from drug manufacturers. On balance, the recent changes would seem to have reduced the amounts that households pay directly for medicine. That contribution fell from 18\% of aggregate costs in 2004 to $7 \%$ in 2006. The share of private-sector contributions to aggregate drug costs is thus very low by international standards, and the proportion is lower than for hospital or outpatient care. This situation is paradoxical, because co-payment mechanisms are generally more effective in restraining demand for medicine than for other forms of care.

45. A new mechanism for monitoring prescriptions for drugs has been launched recently (see Annex 3.A2 for a detailed description). This reform (Law 3697/2008) is based on a new IT system, in line with international practice, which provides detailed information on prescriptions in all public hospitals and private pharmacies. The centralised monitoring of prescriptions will help rationalise and combat abusive prescriptions by enabling comparisons with average behaviours, taking into account the specificities of doctor specialities, geographical areas, population insured by the various sickness funds and pharmaceutical products. This system will take about 6-months to implement and is expected to be fully functional around mid-2010. The authorities estimate that the system would cut prescription costs by up to $30 \%$ generating annual savings of about $€ 2$ billion ( $0.8 \%$ of GDP).

46. To tighten control over the consumption of medicine, other measures ought to be taken. The use of generic drugs, which accounted for only $10 \%$ of the total drug market in 2003, ought to be encouraged (Geitona et al., 2006). The penetration rate of such products is one of the lowest in Europe, demonstrating that Greece lags behind in promoting generics (Vogler et al., 2008). The penetration rate of generics in the drug market no longer protected by patents was $26 \%$ by value and $36.5 \%$ by volume at the beginning of 2008, whereas the corresponding figures were respectively $39.8 \%$ and $48.7 \%$ for the average of 16 European countries and $60.0 \%$ and $71.6 \%$ for the Netherlands (Wildson et al., 2008). Better incentives are needed, and one solution would be to encourage drug prescriptions to be based on active ingredients rather than brands, as in certain regions in Spain (OECD, 2005), and to authorise pharmacists to substitute generic drugs for branded ones. This would be fostered by changing how pharmacists are compensated, 
which is currently based on their margins and encourages them to sell products that are more expensive. As in Switzerland, their compensation should be based in part on set charges for services rendered to customers rather than being tied to sales revenues (OECD, 2006b). Alternatively, pharmacists' margins could be made the same for generics as for branded products with the same active ingredients, as they are in France. Competition in the generic drug market could also be spurred by rescinding the current regulation that sets their prices at a $20 \%$ discount off the price of patent-protected products. Moreover, the use of a system of reference prices that are established on the basis of foreign prices also has its drawbacks, because the system can be manipulated by drug producers (OECD, 2008c). Another option would be to alter the packaging of pharmaceuticals so as to allow sales of single doses, which would avoid waste. Lastly, stricter rules could be adopted to further reduce the pressures exerted by drug producers that try to influence doctors' prescriptions, while the public could be better informed in an effort to scale back unnecessary prescriptions for antibiotics.

\section{Conclusions and recommendations}

47. The Greek health care system has produced relatively favourable outcomes. However, as in the other OECD countries, it is under growing pressure from households' increasing demand for care and for improved quality. The current system cannot cope satisfactorily with this pressure, as evidenced by the population's dissatisfaction with the public health system. It suffers from underfunding which impairs the quality of its services, especially in primary care. The proportion of private medical outlays is high, and unequal access to health care services raises equity issues. Moreover, the management of public resources has serious shortcomings, as reflected, for example, in the large volume of informal payments. Significant reforms are needed to correct these deficiencies and enhance the quality of public health services.

\section{Review the structure of the health care system and its governance}

48. Reforms should revolve around four major objectives (Box 3.2). First, planning and resource allocation, which is hampered by the current lack of uniformity in the organisation and governance of the health care system, ought to be rationalised. It would seem advisable to consolidate all health-related powers, which are currently dispersed throughout the government, within a single ministry. This could contribute, for example, to managing the supply of health care professional to be better in line with the population's present and future health care needs. The fragmentation of the public health care system between the NHS and the many different health funds, administered by different ministries, is another factor that undermines efficient management of resources. The separation between the administration of pensions and health care, which is planned by the government, is necessary, and the creation of a single health insurance fund should be considered. With no choice between funds, their multiplicity and differences in cover are a source of fairness and efficiency problems. The alternative approach, implying the introduction of competition between several funds, would require a more radical change in the functioning of the system without guaranteeing a better quality and equity of medical service supply, while ensuring cost control. ${ }^{16}$ Consolidating the funds would bolster the bargaining power of public insurers and cut the system's administrative costs. Multiple attempts to unify the health funds have failed because of opposition from the most generous funds. It might be possible to reduce resistance to change if a single, compulsory insurance scheme was supplemented by options for voluntary membership of supplemental funds for households wishing to broaden their medical protection.

16. Introducing competition between health insurance funds would for instance require giving insured persons the choice of their funds. Regulation would also be needed to avoid the risk of adverse selection associated with this system. This would imply a radical change in the logic of functioning of the current system. International experience suggests that such an approach lead to a significant rise in management costs, without generating necessarily a better performance. 
49. It would also be advisable to review arrangements for the funding of medical outlays by doing away with transfers to hospitals from the state budget. Administration of all public resources for health care, whether from the budget or from social security contributions, by a single body in charge of funding all care providers would contribute to better resource allocation. The current allocation of resources is skewed in favour of hospital care as opposed to primary care, while too few resources would seem earmarked for prevention. Separating the functions of medical insurer and caregiver by service providers competing amongst themselves could also play a useful role in better determining the relative prices of medical services and improving resource allocation. More generally, allocation should be based more on economic assessments so as to promote medical practices that are cost-effective. However, this would entail substantial progress in filling the major gaps in the collection of information. In this perspective, the modernisation of the hospital accounting system, which is almost completed, should help to remedy the existing deficiencies. In addition, the recent government initiative to establish a committee with the responsibility to introduce the OECD system of health accounts is welcome. Better statistical data are indispensable for enhancing the monitoring of the performances of the health care system and identifying the required actions to correct its problems.

\section{Enhance the quality of public primary health care services}

50. The way practitioners are compensated and other related incentives should be reviewed. Introducing a hybrid system combining capitation payments and fees for service for physicians working for the funds would probably help spur competition in this sector and improve the supply of health care. International evidence shows that a more diversified compensation system, including a fee-for-service component, would increase physicians' activity rate (Simoens and Hurst, 2006). Such a reform could be combined with a ban on dual practice, which also impairs the quality of public services. More generally, reducing the number of doctors, or of those working half-time, and increasing their compensation in line with their productivity, would be one option to explore.

51. Changing how practitioners are paid could also help scale back the prevalence of informal payments, which constitutes one of the biggest problems in the Greek health care system. It is important to factor in the loss of income that medical service-providers would incur if these practices were eliminated. ${ }^{17}$ In the hospital sector, salary differentiation between specialities might be necessary to attract more doctors to fields for which demand and "bribes" are high. Another option would be to implement a bonus system tied to the productivity and quality of services (rate of client vaccination, suitable follow-up of diabetics, etc.). Another possibility would be to formalise informal payments in the form of a patient charge for outpatient care, with provisions for exemptions if need be. Lastly, it is essential to establish effective mechanisms for supervising and auditing payments. Efforts are crucial to restoring trust and enhancing transparency, as well as the accountability of care providers. A multi-pronged strategy is probably needed to put an end to informal payments. It would also demand strong political determination to combat and sanction these illegal practices.

52. Improving the quality of public primary services also requires greater continuity in the supply of health care. The measures that the government has recently envisaged, such as introducing a system of referring physicians and medical protocols, are a step in the right direction. These initiatives could be supplemented with the introduction of portable health record books (carnets de santé), along with incentives for patients to show them systematically at each medical consultation. These measures would foster care that is more patient-oriented and avoid unnecessary duplication of tests or consultations. Measures would also be needed to improve the supervision and control of diagnostic services outsourced to the private sector. To compensate for the low number of general practitioners, practices in the outpatient

17. The amount of informal payments for heart surgery, for example, would suggest tax evasion representing $85 \%$ of aggregate income for the practitioners in question (Siskou et al., 2008). 
sector could be developed with multidisciplinary teams combining medical and non-medical personnel, including persons specialised in the co-ordination of primary health care services (Hofmarcher, Oxley and Rusticelli, 2007). This would undoubtedly entail training more nurses.

\section{Modernise hospital administration}

53. Health care reform should also focus on modernising hospital administration. Existing mechanisms for controlling public outlays lead to excessive and inefficient micromanagement of NHS establishments by the Ministry of Health. Improving the efficiency of hospitals entails completing the upgrading of their accounting systems, appointing qualified managers, widening hospitals' managerial scope and revamping their funding system. This should be based on a comprehensive budget that is determined on a forward-looking, binding basis, which should gradually incorporate cost assessments by category of pathology (Diagnostic Related Group, DRG) rather than by length of hospitalisation.

\section{Continue efforts to tighten control over pharmaceutical spending}

54. The recently launched system for monitoring prescriptions for drugs is an important contribution to controlling pharmaceutical expenditures. A variety of complementary measures could be adopted to improve the control over this spending: these include an increase in patients' contribution to costs to rebalance the structure of private spending, which would also reduce out-of-pocket expenditure for health services; regulations more favourable to the use of generic drugs; a revision of drug packaging standards, and reforms of the system for compensating pharmacists. Restoration of the positive list of reimbursed drugs, excluding all possibilities for exemption, should also be considered. While the effectiveness of any one of these measures, taken on its own, may potentially be limited, a programme encompassing various actions would certainly prove more effective.

\section{Box 2. Recommendations for health policy reforms}

\section{Review the structure of the health care system and its governance}

- $\quad$ Consolidate all powers within a single ministry. Separate health insurance funds from pension funds, as planned by the government.

- $\quad$ Consolidate the funds and hospitals in one entity, such as the NHS. Make basic medical cover uniform for the entire population.

- $\quad$ Separate the functions of insurer and care provider and develop an internal market for health care services. Discontinue administrative regulation of the prices of medical goods and services and develop mechanisms for negotiations between a single insurance fund and health care providers.

- Tailor the management of medical demography to the population's present and future health care needs. Inter alia, increase the number of nurses and the proportion of general practitioners. Avoid training more specialists than are warranted in view of the outlook for care growth.

- Improve the collection and administration of medical statistics. Rapidly introduce the OECD system of health accounts. Create a body to dispense advice on economic assessment of health goods and services and medical practices, such as the National Institute for Clinical Excellence in the United Kingdom.

- Bolster efforts in the realm of prevention, as well as incentives to adopt healthier lifestyles. Continue to raise the excise tax on tobacco.

Enhance the quality of public primary health care services

- Develop a system of referring physicians. This would require incentives to restructure the medical profession, increasing the proportion of general practitioners and encouraging specialists to shift to general practice.

- Introduce portable health record books along with incentives for patients to show them systematically at each medical consultation. 
- Bolster supervision of medical practices to limit the spread of informal payments. Introduce formal copayments for outpatient care.

- Review how doctors are paid. Introduce a hybrid system combining capitation payments and fees for service. Reinforce the incentives for physicians to work in remote areas. Differentiate the compensation of hospital doctors between specialities. Put an end to dual practice.

\section{Modernise hospital administration}

- Complete the replacement of the cash-based accounting system with a transaction-based system. Introduce a cost accounting system.

- Pursue efforts to rationalise the management of public hospital procurement, improve transparency and achieve economies of scale.

- Professionalise hospital administration by appointing qualified managers. Extend the administrative autonomy of hospitals.

- Institute a forward-looking system of hospital funding which would ultimately be based on pathological categories (DRG).

- Exercise caution in using private/public partnerships to develop health care infrastructure. Evaluate selected projects cautiously and transparently.

Continue efforts to tighten control over pharmaceutical expenditure

- Promote the distribution of generic drugs. Encourage physicians to prescribe on the basis of active ingredients rather than branded products. Allow pharmacists to substitute generics for branded drugs.

- Consider reviewing how pharmacists are compensated to reduce incentives to sell the most expensive drugs.

- $\quad$ Review packaging standards for pharmaceutical products so as to limit waste.

- Increase co-payments.

- Restore a positive list of reimbursed drugs, with very limited possibilities for derogation.

- $\quad$ Adopt stricter rules to reduce the influence of pharmaceutical laboratories on doctors' prescriptions. Improve public information so as to limit demand for unnecessary prescriptions for antibiotics.

\section{Bibliography}

Afonso, A. et al., (2003), "Public sector efficiency: an international comparison", Working Paper No. 242, European Central Bank.

Aletras, V. (1999), "A comparison of hospital scale effects in short-run and long-run cost functions". Health Economics, Vol. 8, No. 6.

Allin, S. et al, (2005), "Paying for 'free' health care: the conundrum of informal payments in postcommunist Europe",

Ballas, A. and H. Tsoukas, (2004) "Measuring nothing: The case of the Greek National Health System, Human Relations, Vol. 57, No. 6. 
Contiades X., Golna C. and Souliotis K. (2007), "Pharmaceutical Regulation at the Crossroad of Change: Economic, Political and Constitutional Considerations for a new Regulatory Pradigm", Vol. 82, No 1.

Costacou, T. et al., (2003) "Tracing the Mediterranean diet through principle components and cluster analysis in the Greek population", European Journal of Clinical Nutrition, Vol. 57, No. 11.

Davaki, K. and E. Mossialos, (2005), "Plus ça change: Health sector reforms in Greece", Journal of Health Politics, Policy and Law, Vol. 30, No. 1-2.

Economic and Social Council of Greece, (2005), National health and social care system and other provisions, Opinion 128, Athens (in Greek).

Economou, Ch. et al., (2004), Fairness of health financing in the Greek health care sector, $8^{\text {th }}$ International Conference on System Science in Health Care: Health care systems. Public and private management.

Garcias-Mariñoso, B. and I. Jalovac (2003), "GPs' payment contracts and their referral practice", Journal of Health Economics, Vol. 22.

Geitona, M. et al., (2006), "Generics market in Greece: The pharmaceutical industry's beliefs", Health Policy, Vol. 79, No. 1.

Geitona, M. et al., (2007), "Determinants of healthcare utilization in Greece: Implications for decisionmaking", The European Journal of General Practice, Vol. 13, No. 3, pp. 144-150.

Giokas, D. (2001), "Greek hospitals: how well their resources are used", Omega, Vol. 29, No. 5.

GSNE, (2006), "Health Expenditure", Household Budget Surveys 2004/5, Ministry of Economy.

Hofmarcher, M., H. Oxley, and E. Rusticelli, (2007), 'Improved Health System Performance through better Care Coordination", OECD Health Working Papers, No. 30, Paris.

Huisman, M. et al., (2003), "Socioeconomic inequalities in morbidity among the elderly; a European overview", Social Science and Medicine, Vol. 57, No. 5.

IKA (2005), Statistical Bulletin 2005, Athens (in Greek).

Joumard, I. et al., (2008), "Health Status Determinants: Lifestyle, Environment, Health Care Resources and Efficiency", OECD Economics department Working Papers, No. 627, Paris.

Kontodimopoulos, N. et al., (2007), "The effect of environmental factors on technical and scale efficiency of primary health care providers in Greece", Cost Effectiveness and Resource Allocation, Vol. 5/14.

Kyriopoulos, J. and G. Karalis (1997), "Recent Developments in Hidden Economy Activities in the Health Sector in Greece", Health Review (Athens), 8(49).

Kyriopoulos, J. (2004), "Informal payments in the health sector: Some evidence and research issues", in J. Kyriopoulos (ed.), Health systems in the world: From evidence to policy, Athens.

Liaropoulos, L. and E. Tragakes, (1998), "Public/private financing in the Greek health care system: implications for equity", Health Policy, Vol. 43, No. 2.

Liaropoulos, L. et al., (2008), "Informal payments in public hospitals in Greece", Health Policy, in press.

Macinko, J. et al., (2003), "The Contribution of Primary Care Systems to Health Outcomes within Organisation of Economic Cooperation and Development (OECD) Countries, 1970-1998", HSR: Health Services Research, Vol. 38, No. 3. 
Mergoupis, T. (2003), "Income and Utilisation of Health Services in Greece", In Venieris, D. and C. Papatheodorou (eds), Social Policy in Greece: Challenges and Prospects, Athens.

Mitropoulos, J. and A. Sissouras (2004), "Rationalising the allocation of central resources to the health care regions in Greece", Applied Health Economics and Health Policy, Vol. 3.

Mossialos, E. et al., (2005a), "Analysing the Greek health system: A tale of fragmentation and inertia, Health Economics, Vol. 14, Supplement.

Mossialos, E. et al., (2005b), "An investigation of Caesarean sections in three Greek hospitals: The impact of financial incentives and convenience", European Journal of Public Health, Vol. 15, No. 3.

Nolte, E. and C. McKee (2008), "Measuring the Health of Nations: Updating an Earlier Analysis", Health Affairs, Vol. 27, No. 1, January/February.

OECD, (2004), "Increasing value for money in health systems: The quest for efficiency", Towards highperforming health systems, Paris.

OECD, (2005), OECD Economic Surveys: Spain, Paris.

OECD, (2006a), "Projecting OECD Health and Long-term Care Expenditures: What are the Main Drivers?", OECD Economic Department Working Papers, No. 477, Paris.

OECD, (2006b), OECD Economic Surveys: Switzerland, Paris.

OECD, (2007), OECD Regions at a Glance, Paris.

OECD, (2008a), "The Looming Crisis in the Health Workforce: How Can OECD Countries Respond?" OECD Health Workforce Surveys, Paris

OECD (2008b), Public-Private Partnerships: In Pursuit of Risk Sharing and Value for Money, Paris.

OECD (2008c), Pharmaceutical Pricing Policies in a Global Market, Paris

Pappa, E. and D. Niakas (2006), "Assessment of health care needs and utilisation in a mixed public-private system: the case of the Athens area", Open Access, http://www.biomedcentral.com.

Rovithis, D. (2006), "Health economic evaluation in Greece", International Journal of Technology Assessment in Health Care, Vol. 22, No. 3.

Saltman, R. et al., (2008), "Primary care in the driver's seat? Organisational reform in European primary care", European Observatory on Health Systems and Policies Series, Open University Press.

Simoens, S. and J. Hurst, (2006), "The Supply of Physician Services in OECD Countries", OECD Health Working Papers, No. 21, Paris.

Siskou, O. et al., (2008), "Private health expenditure in the Greek health care system: Where truth ends and the myth begins", Health Policy, Article in Press, Elsevier.

Souliotis, K. and J. Kyriopoulos (2003), "The hidden economy and health expenditures in Greece: measurement problems and policy issues", Applied Health Economics and Health Policy, Vol. 2/3.

Starfield, B. and L. Shi (2002), "Policy-relevant determinants of health: an international perspective", Health Policy 2002, No. 60.

Starfield, B. et al., (2005), "Contribution of Primary Care to Health Systems and Health", The Milbank Quarterly, Vol. 83, No. 3, Milbank Memorial Fund, Blackwell Publishing. 
Starfield, B. (2005), Outcome of Different Health Systems Dependent on the Role and Organisation of Primary Care, EPA conference in Berlin, http://www.equip.ch/files/8/starfield_berlin_jan05.pdf

Tanner, M. (2008), "The grass is not always greener: A look at National Health Care Systems Around the World", Policy Analysis, No. 613, CATO Institute.

Tountas, Y. et al. (2005), "The unexpected growth of the private health sector in Greece", Health Policy, No. 74.

Trichopoulou, A. et al., (2003), "Adherence to a Mediterranean diet and survival to a Greek population", The New England Journal of Medicine, Vol. 348, No. 26.

Van Doorslaer, E. and C. Masseria ( 2004), "Income-related inequality in the use of medical care in 21 OECD countries", OECD Health working paper No14.

Vogler, S., C. Habi, C. Leopold, I. Rosian-Schikuta, K. Joncheere and T. Thomsen (2008), Pharmaceutical Pricing and Reimbursement Information, Report commissioned by the European Commission.

WHO, (1996), Health Care Systems in Transition: Greece, Regional office for Europe, Copenhagen.

WHO, (2004), "Comparison of patient evaluations of health care quality in relation to WHO measures of achievement in 12 European countries", Bulletin of the World Health Organisation.

WHO/EURO, (2006), Highlights on health in Greece 2004, World Health Organisation Europe, Copenhagen. http://www.euro.who.int/highlights http://www.euro.who.int/highlights

WHO, (2008), "Primary Health Care: Now more than ever", The World Health Report 2008.

Wildson T., J. Attridge and A. Berdellima (2008), "Factors Affecting Generic Entry in Europe", CRA International, June.

Xu, K., D. Evans, K. Kawabata, R. Zeramdini, J. Klavus and C. Murray (2003), "Household catastrophic health expenditure: a multicountry analysis", The Lancet, Vol. 362, July.

Yfantopoulos, J. (2008), "Pharmaceutical pricing and reimbursement reforms in Greece", European Journal of Health Economics, Vol. 9, No. 1.

Zavras, A. et al., (2002), "Using DEA to evaluate efficiency and formulate policy within a Greek National Primary Health Care Network", Journal of Medical Systems, Vol. 26, No. 4. 


\section{Annex 1.}

\section{Data envelopment analysis}

1. This annex provides the technical details of the data envelopment analysis (DEA) used in this survey to measure the health system efficiency of OECD countries. The DEA technique is commonly used to assess health system efficiency because of the ease with which it deals with complex problems without restrictive statistical conditions (Cooper et al, 2004 and 2006).

2. This survey uses a modified version of the DEA developed by Joumard et al (2008) ${ }^{18}$. DEA creates an efficiency frontier by optimising the input to output ratio, a common measure of efficiency, to calculate efficiency scores for each country. Figure A1.1 shows how efficiency scores can be measured by an input-oriented approach (minimising input without reducing output) or an output-oriented approach (improving output without additional input). The efficiency scores measure the distance between individual countries and the efficiency frontier. In this survey it is assumed that the DEA efficiency frontier has nonincreasing returns to scale. Figure A1.1 shows that the efficiency frontier is convex inward. This is because the marginal cost of producing units of health beyond a certain level becomes higher than average.

\section{Figure A1.1. A stylised example of an efficiency frontier and non-increasing returns to scale} A scenario with one input and one output, 2006 or latest available data

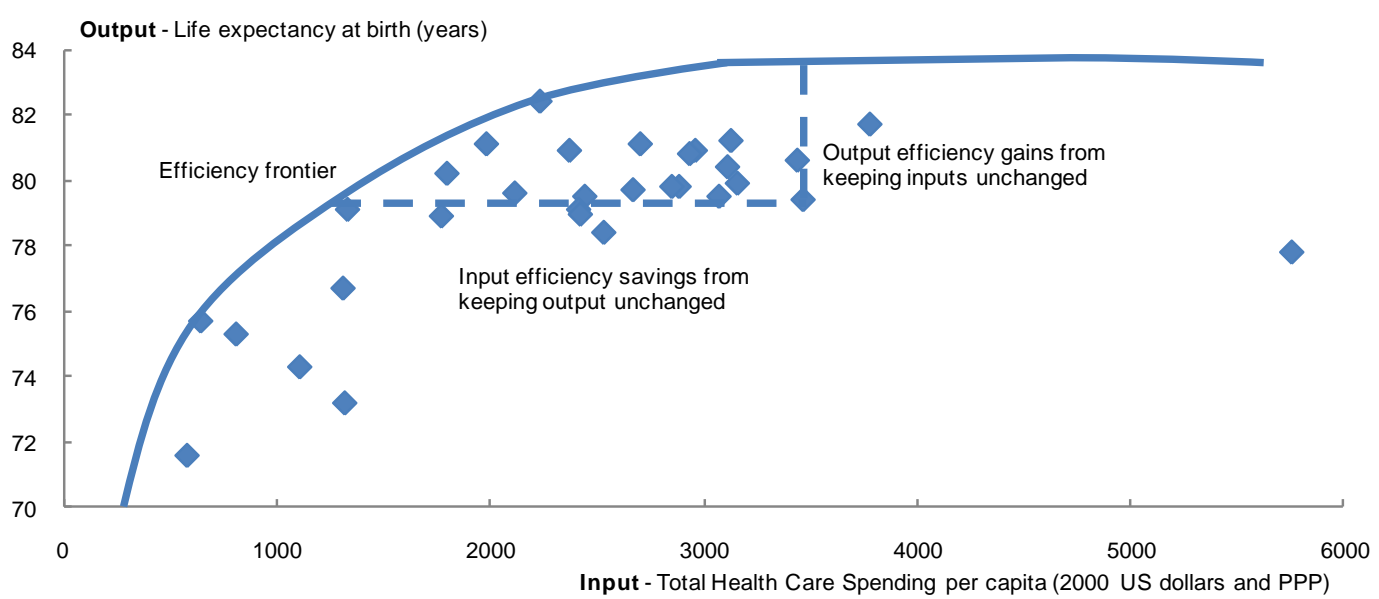

Source: OECD Health Data 2008

18. Joumard, et al., (2008) used the PISA Index of Economic Social and Cultural Status to measure socioeconomic conditions. As this data is only available for 2004, this survey uses GDP per capita to measure of socio-economic conditions. Joumard, et al., (2008) also used GDP per capita in alternative models to test the sensitivity of their original results. 
3. This survey uses two output-oriented DEA models to measure health system efficiency over time for OECD countries by looking at two points in time (1990 and 2006). The first model measures health system efficiency in terms of cost efficiency. It includes one output, life expectancy (LE) at birth of the total population, and three inputs related to health care production: (1) health care resources (measured by health care spending per capita); (2) socio-economic conditions (measured by GDP per capita); and (3) lifestyle factor (represented by per capita consumption of fruits and vegetables). The second model measures health system efficiency in terms of technical efficiency by replacing health care spending per capita with the number of health practitioners. Two models are used to ensure the consistency of the DEA results.

4. The efficiency scores are upwardly biased because the calculation benchmark from the observed efficiency frontier is always lower than that of the theoretical efficiency frontier (Staat, 2006). This annex uses the statistical technique "bootstrapping"19 to correct potential upward bias and provide confidence intervals for the efficiency scores. The estimation of confidence intervals is important because the statistical estimators of the frontier are sensitive to selection errors, statistical noise and outliers. Another limitation of DEA is that while it provides a good estimate of "relative" efficiency, it does not allow for a quick convergence to "absolute" efficiency. Countries with the best use of inputs may be perceived as efficient when in fact they are not because theoretical maximum efficiency is unknown.

\section{Bibliography}

Cooper, W. W. et al., (2004), "Handbook on data envelopment analysis", Kulwer Academic Publishers, ISBN 1-4020-7797-1.

Cooper, W. W. et al., (2006), "Introduction to data envelopment analysis and its uses", Springer, ISBN-10: 0-387-29122-9 (e-book).

Joumard, I. et al., (2008), "Health Status Determinants: Lifestyle, Environment, Health Care Resources and Efficiency", OECD Economics Department Working Papers, No. 627, Paris.

Staat, M., (2006), "Efficiency of hospitals in Germany: a DEA-bootstrap approach", Applied Economics, No. 38, pp. 2255-2263.

19. The bootstrapping method creates an appropriately large number of resample $S^{*}$ by repeatedly sampling with replacement from the original sampled data set $S$. It measures the distance between the original $S$ to $S^{*}$ for each observation. It then creates a bootstrap distribution based on the statistics collected through solving the bootstrap estimator. This method can correct any finite sample bias in the estimators of the distance functions and calculate the desired confidence intervals. 
Annex 2.

\section{A new mechanism for monitoring prescriptions for drugs}

1. The authorities have announced a reform initiative to reduce public spending on prescription medicines and pharmaceutical materials. They see the implementation of an efficient IT system for monitoring and controlling prescription medicines and pharmaceutical materials as a catalyst to managing public resources in an effective and transparent way. Specifically, the introduction of a national electronic monitoring system is the backbone of the mechanism to control costs. Among the many benefits, the initiation of a monitoring system will allow the immediate collection of the legislated $3 \%$ manufacturers' rebate, and will generate estimated annual revenues of about $€ 140$ million.

2. A modern IT system monitoring prescriptions at all public hospitals and private pharmacies will provide the necessary transparency controls as well as the appropriate intervention mechanisms. The system will use modern information and communication technologies - in line with international practices - for the implementation of electronic monitoring and data processing of prescriptions, and for links to the outlets. The system will involve:

- The installation of a central facility for electronic gathering and processing of prescription and health material data from pharmacies.

- The processing of data for rapid calculation and documented financial reporting, securing public revenue collection.

- The leveraging of a Management Information System to enable:

- central policy enforcement and scenarios management.

- the application of regulatory interventions in health.

- mechanisms to combat the abuse of prescriptions.

- rationalisation mechanisms for health expenditure.

- complete transparency of the system.

3. The new system lays the foundation for effective government interventions for the modernization of healthcare, and has the ability to extend beyond the control of medicines and materials to diagnostic tests. Moreover, it is fully in line with the formulation of national and EU policy in the healthcare sector. There is an aggressive implementation plan that aims to bring about an immediate impact on public finances, and to accelerate the procedures for contract award. 


\section{WORKING PAPERS}

The full series of Economics Department Working Papers can be consulted at www.oecd.org/eco/working_papers/

721. Is there a case for price-level targeting?

(August 2009) Boris Cournède and Diego Moccero

720. The challenge of restoring French competitiveness (August 2009) Rafal Kierzenkowski

719. Improving the functioning of the Slovenian labour market (August 2009) Isabell Koske

718. What drives sovereign risk premiums? An analysis of recent evidence from the Euro Area (July 2009) David Haugh, Patrice Ollivaud, and David Turner

717. The English National Health Service: an economic health check

(July 2009) Peter Smith and Maria Goddard

716. Financial stability in the United Kingdom: Banking on prudence (July 2009) Philip Davis

715. Economic growth and the role of taxation- disaggregate data (July 2009) Gareth D. Myles

714. Economic growth and the role of taxation-Aggregate data (July 2009) Gareth D. Myles

713. Economic growth and the role of taxation - Theory (July 2009) Gareth D. Myles

712. The effectiveness of education and health spending among Brazilian municipalities (July 2009) Luiz de Mello and Mauro Pisu

711. The bank lending channel of monetary transmission in Brazil: A VECM approach (July 2009) Luiz de Mello and Mauro Pisu

710. How does decentralised minimum-wage setting affect unemployment and informality? The case of Indonesia

(July 2009) Margherita Comola and Luiz de Mello

709. Intergenerational social mobility in European OECD countries (July 2009) Orsetta Causa, Sophie Dantan and Åsa Johansson

708. Equity in student achievement across OECD countries: an investigation of the role of policies (July 2009) Orsetta Causa and Catherine Chapuis

707. Intergenerational social mobility

(July 2009) rsetta Causa and Åsa Johansson 
706. Taxes or grants: what revenue source for sub-central governments?

(July 2009) Hansjörg Blöchliger and Oliver Petzold

705. The spending power of sub-central governments: a pilot study

(July 2009) Steffen Bach, Hansjörg Blöchliger and Dominik Wallau

704. Price and volume elasticities of Brazilian foreign trade: A profit function approach (July 2009) Luiz de Mello and Mauro Pisu

703. Current account sustainability in Brazil: A non linear approach (July 2009) Luiz de Mello and Matteo Mogliani

702. The incentives to participate in and the stability of international climate coalitions: a game-theoretic approach using the WITCH Model

(July 2009) Valentina Bosetti, Carlo Carraro, Enrica De Cian, Romain Duval, Emanuele Massetti and Massimo Tavoni

701. The economics of climate change mitigation: how to build the necessary global action in a costeffective manner

(June 2009) Jean-Marc Burniaux, Jean Chateau, Rob Dellink, Romain Duval and Stéphanie Jamet

700. Capital inflows, household debt and the boom bust cycle in Estonia (June 2009) Zuzana Brixiova, Laura Vartia and Andreas Wörgötter

699. The effect of financial crises on potential output: new empirical evidence from OECD countries (May 2009) Davide Furceri and Annabelle Mourougane

698. Employment - productivity trade-off and labour composition (May 2009) Hervé Boulhol and Laure Turner

697. Labour market flexibility in Estonia: what more can be done? (May 2009) Zuzana Brixiova

696. Structural policies to overcome geographic barriers and create prosperity in New Zealand (April 2009) Yvan Guillemette

695. Ten years of product market reform in OECD countries - insights from a revised PMR indicator (April 2009) Anita Wölfl, Isabelle Wanner, Tomasz Kozluk and Giuseppe Nicoletti

694. Structural reforms and the benefits of the enlarged eu internal market (April 2009) Jens Arnold, Peter Höller, Margaret Morgan and Andreas Wörgötter

693. Co-benefits of climate change mitigation policies: literature review and new results (April 2009) Johannes Bollen, Bruno Guay, Stéphanie Jamet and Jan Corfee-Morlot

692. The impact of monetary and commodity fundamentals, macro news and central bank communication on the exchange rate: Evidence from South Africa (April 2009) Balázs Égert

691. Assessing the impacts of climate change: a literature review (April 2009) Stéphanie Jamet and Jan Corfee-Morlot 
690. The determinants of employment and earnings in Indonesia: a multinomial selection approach (April 2009) Margherita Comola and Luiz de Mello

689. Inflation responses to recent shocks: do G7 countries behave differently (April 2009) Lukas Vogel, Elena Rusticelli, Pete Richardson, Stéphanie Guichard and Christian Gianella

688. Infrastructure investment in network industries: the role of incentive regulation and regulatory independence

(March 2009) Balázs Égert

687. Government consumption volatility and the size of nations

(March 2009) Davide Furceri and Marcos Poplawski Ribeiro

686. Infrastructure investment: links to growth and the role of public policies (March 2009) Balázs Égert and Tomasz Kozluk and Douglas Sutherland

685. Infrastructure and growth: empirical evidence

(March 2009) Balázs Égert and Tomasz Kozluk and Douglas Sutherland

684. The effects of population structure on employment and productivity (March 2009) Hervé Boulhol

683. The macroeconomic consequences of banking crises in OECD countries (March 2009) David Haugh, Patrice Ollivaud and David Turner 